\title{
Molecular mechanism of nucleotide excision repair
}

\author{
Wouter L. de Laat, Nicolaas G.J. Jaspers, and Jan H.J. Hoeijmakers ${ }^{1}$ \\ Medical Genetic Center, Department of Cell Biology and Genetics, Erasmus University, \\ 3000 DR Rotterdam, The Netherlands
}

From its very beginning, life has faced the fundamental problem that the form in which genetic information is stored is not chemically inert. DNA integrity is challenged by the damaging effect of numerous chemical and physical agents, compromizing its function. To protect this Achilles heel, an intricate network of DNA repair systems has evolved early in evolution. One of these is nucleotide excision repair (NER), a highly versatile and sophisticated DNA damage removal pathway that counteracts the deleterious effects of a multitude of DNA lesions, including major types of damage induced by environmental sources. The most relevant lesions subject to NER are cyclobutane pyrimidine dimers (CPDs) and (6-4) photoproducts (6-4PPs), two major kinds of injury produced by the shortwave UV component of sunlight. In addition, numerous bulky chemical adducts are eliminated by this process. Within the divergent spectrum of NER lesions, significant distortion of the DNA helix appears to be a common denominator. Defects in NER underlie the extreme photosensitivity and predisposition to skin cancer observed with the prototype repair syndrome xeroderma pigmentosum (XP). Seven XP complementation groups have been identified, representing distinct repair genes XPA-G (discussed in detail below).

In the last decade, all key NER factors have been cloned and the core of the 'cut-and-paste' reaction has been reconstituted in vitro from purified components. Recently, XPC (complexed to hHR23B) has been identified as a DNA-damage sensor and repair-recruitment factor. The general transcription factor complex TFIIH, containing the XPB and XPD helicases, mediates strand separation at the site of the lesion. XPA verifies the damage in an open DNA conformation and is crucial in the assembly of the remainder of the repair machinery. Replication protein A (RPA) stabilizes the opened DNA complex and is involved in positioning the XPG and ERCC1-XPF endonucleases responsible for the DNA incisions around the lesion. After removal of the damagecontaining oligonucleotide, typically 24-32 nucleotides in length, general replication factors fill in the remaining gap and close it.

${ }^{1}$ Corresponding author.

E-MAIL Hoeijmakers@gen.fgg.eur.nl; FAX 31104089468.
Two modes of NER can be distinguished: repair of lesions over the entire genome, referred to as global genome NER (GG-NER), and repair of transcription-blocking lesions present in transcribed DNA strands, hence called transcription-coupled NER (TC-NER). Most XP groups harbor defects in a common component of both NER subpathways. GG-NER is dependent on the activity of all factors mentioned above, including the GGNER-specific complex XPC-hHR23B. The rate of repair for GG-NER strongly depends on the type of lesion. For instance, 6-4PPs are removed much faster from the genome than CPDs, probably because of differences in affinity of the damage sensor XPC-hHR23B. In addition, the location (accessibility) of a lesion influences the removal rate in vivo. In TC-NER, damage is detected by the elongating RNA polymerase II complex when it encounters a lesion. Interestingly, a distinct disorder, Cockayne syndrome (CS), is associated with a specific defect in transcription-coupled repair. The identification of two complementation groups (CS-A and CS-B) shows that at least two gene products are specifically needed for fast and efficient repair of transcribed strands. Phenotypically, CS is a very pleiotropic condition characterized by photosensitivity as well as severe neurological, developmental, and premature aging features. Most of these symptoms are not seen even with totally NERdeficient XP patients. The additional symptoms of CS suggest that transcription-coupled repair and/or the CS proteins have functions beyond NER. Also, non-NERspecific lesions (such as oxidative damage) that stall transcription elongation appear to be removed in a transcription-coupled fashion, linking a blocked polymerase to multiple repair pathways. Intriguingly, some XP-B, $\mathrm{XP}-\mathrm{D}$, and XP-G patients display CS features combined with XP manifestations. Yet other XP-B and XP-D individuals suffer from the CS-like brittle-hair syndrome trichothiodystrophy (TTD). This clinical conundrum points to additional roles of these NER factors as well. A recent mouse model for TTD has linked mutations in the XPD subunit of the dual functional TFIIH complex with deficiencies in basal transcription underlying at least some of the TTD manifestations. Thus, NER defects are associated with a surprisingly wide clinical heterogeneity due to additional functions of the NER factors involved. 
This review focuses on the core NER components of mammalian cells, integrating recent advances into a detailed model for the molecular reaction mechanism. Various aspects of NER and associated syndromes have been comprehensively summarized in previous reviews (see Hanawalt and Mellon 1993; Hoeijmakers 1994; Friedberg et al. 1996; Sancar 1996; Wood 1996, 1997; Bootsma et al. 1997; de Boer and Hoeijmakers 1999|.

\section{XPC-hHR23B}

$\mathrm{XPC}$ is the sole XP factor dispensable for TC-NER and is restricted to global genome NER (Venema et al. 1990a, 1991; van Hoffen et al. 1995). The 125-kD XPC protein is complexed with the 58-kD hHR23B gene product, one of the two human homologs of the yeast NER factor Rad23 (Masutani et al. 1994) (Table 1) (for proteins and domains, see Fig. 1). hHR23B stimulates XPC activity in vitro (Sugasawa et al. 1996), probably in a structural rather than a catalytic fashion, as the 54-amino acid XPC-binding domain of hHR23B is already sufficient for
XPC stimulation (Masutani et al. 1997). hHR23B is much more abundant than XPC in mammalian cells, and like hHR23A, the other human homolog of Rad23, mostly exists in a free form in the cell (Masutani et al. 1994; van der Spek et al. 1996). hHR23A can substitute for hHR23B in binding and stimulating XPC in vitro, suggesting some functional redundancy (Sugasawa et al. 1997). Yeast Rad23 and its two mammalian derivatives harbor a ubiquitin-like moiety at their amino terminus (Masutani et al. 1994; Fig. 1), pointing to additional engagements in the ubiquitin pathway of protein (in)stability. In Saccharomyces cerevisiae, this domain is indispensable for the repair function of $\operatorname{Rad} 23$ (Watkins et al. 1993; Mueller and Smerdon 1996).

The specific role of XPC-hHR23B in GG-NER has been obscure for quite some time. XPC was detected in partially purified TFIIH fractions after seven chromatographic steps; and in $S$. cerevisiae, in vitro binding between the XPC homolog Rad4 (Table 1) and yTFIIH was reported (Bardwell et al. 1994; Drapkin et al. 1994), suggesting a direct interaction between these two protein

Table 1. Core NER factors

\begin{tabular}{|c|c|c|c|c|c|c|c|}
\hline \multicolumn{3}{|c|}{ NER factor } & \multicolumn{5}{|c|}{ Subunits } \\
\hline name & function in NER & $\begin{array}{l}\text { (additional) } \\
\text { engagements }\end{array}$ & name & $\begin{array}{l}\text { protein } \\
\text { size (aa) }\end{array}$ & $\begin{array}{l}\text { rodent } \\
\text { mutant }\end{array}$ & $\begin{array}{l}\text { S. cerevisiae } \\
\text { homolog }\end{array}$ & remarks \\
\hline \multirow[t]{2}{*}{ XPC-hHR23B } & \multirow[t]{2}{*}{$\begin{array}{l}\text { damage sensor and } \\
\text { repair recruitment } \\
\text { factor }\end{array}$} & \multirow[t]{2}{*}{$\begin{array}{l}\text { only in GG-NER; } \\
\text { not involved in } \\
\text { TC-NER }\end{array}$} & hHR23B & 940 & & $\operatorname{Rad} 23$ & $\begin{array}{l}\text { affinity for damaged } \\
\text { DNA } \\
\text { stimulates XPC } \\
\text { activity in vitro }\end{array}$ \\
\hline & & & hHR23A & 363 & & $\operatorname{Rad} 23$ & $\begin{array}{l}\text { can substitute } \\
\text { for hHR23B } \\
\text { in vitro }\end{array}$ \\
\hline \multirow[t]{9}{*}{ TFIIH } & \multirow{9}{*}{$\begin{array}{l}\text { catalyzes open complex } \\
\text { formation around the } \\
\text { lesion and facilitates } \\
\text { repair complex } \\
\text { assembly }\end{array}$} & \multirow{5}{*}{$\begin{array}{l}\text { basal RNA Pol II } \\
\text { transcription } \\
\text { cell cycle } \\
\text { regulation (?) }\end{array}$} & $\mathrm{XPB}$ & 782 & \multirow{9}{*}{$\begin{array}{l}\text { ERCC3 } \\
\text { ERCC2 }\end{array}$} & $\operatorname{Rad} 25 /$ SSL2 & $3^{\prime} \rightarrow 5^{\prime}$ helicase \\
\hline & & & $\mathrm{XPD}$ & 760 & & $\operatorname{Rad} 3$ & $5^{\prime} \rightarrow 3^{\prime}$ helicase \\
\hline & & & p34 & 303 & & TFB4 & DNA binding? \\
\hline & & & $\mathrm{p} 44$ & 395 & & SSL1 & DNA binding? \\
\hline & & & p62 & 548 & & TFB1 & \\
\hline & & additional non- & p52 & 462 & & TFB2 & \\
\hline & & NER- specific & Mat1 & 309 & & TFB3 & CAK subcomplex \\
\hline & & role in transcrip- & Cdk7 & 346 & & $\operatorname{Kin} 28$ & CAK subcomplex \\
\hline & & $\begin{array}{l}\text { tion-coupled } \\
\text { repair (?) }\end{array}$ & Cyclin $\mathrm{H}$ & 323 & & CCL1 & CAK subcomplex \\
\hline XPA & $\begin{array}{l}\text { binds damaged DNA } \\
\text { and facilitates } \\
\text { repair complex } \\
\text { assembly }\end{array}$ & & XPA & 273 & & Rad14 & $\begin{array}{l}\text { affinity for single- } \\
\text { stranded and } \\
\text { damaged DNA }\end{array}$ \\
\hline \multirow[t]{3}{*}{ RPA } & \multirow{3}{*}{$\begin{array}{l}\text { stabilizes opened } \\
\text { DNA complex and } \\
\text { positions nucleases }\end{array}$} & replication & RPA70 & 616 & & Rfal & ssDNA binding \\
\hline & & \multirow[t]{2}{*}{ recombination } & RPA32 & 270 & & Rfa2 & ssDNA binding \\
\hline & & & RPA14 & 121 & & Rfa3 & \\
\hline $\mathrm{XPG}$ & $\begin{array}{l}\text { catalyzes } 3^{\prime} \text { incision } \\
\text { and stabilizes full } \\
\text { open complex }\end{array}$ & $\begin{array}{l}\text { additional non-Ner- } \\
\text { specific role in } \\
\text { transcription- } \\
\text { coupled repair (?) }\end{array}$ & XPG & 1186 & ERCC5 & $\operatorname{Rad} 2$ & $\begin{array}{l}\text { Member of FEN-1 } \\
\text { family of } \\
\text { structure-specific } \\
\text { nucleases }\end{array}$ \\
\hline \multirow[t]{2}{*}{ ERCC1-XPF } & \multirow[t]{2}{*}{ catalyzes $5^{\prime}$ incision } & $\begin{array}{l}\text { interstrand cross-link } \\
\text { repair }\end{array}$ & ERCC1 & 297 & ERCC1 & $\operatorname{Rad} 10$ & \multirow[t]{2}{*}{$\begin{array}{l}\text { structure-specific } \\
\text { endonuclease }\end{array}$} \\
\hline & & $\begin{array}{l}\text { recombination via } \\
\text { single-strand } \\
\text { annealing }\end{array}$ & $\mathrm{XPF}$ & 905 & ERCC4 & Rad1 & \\
\hline
\end{tabular}


de Laat et al.

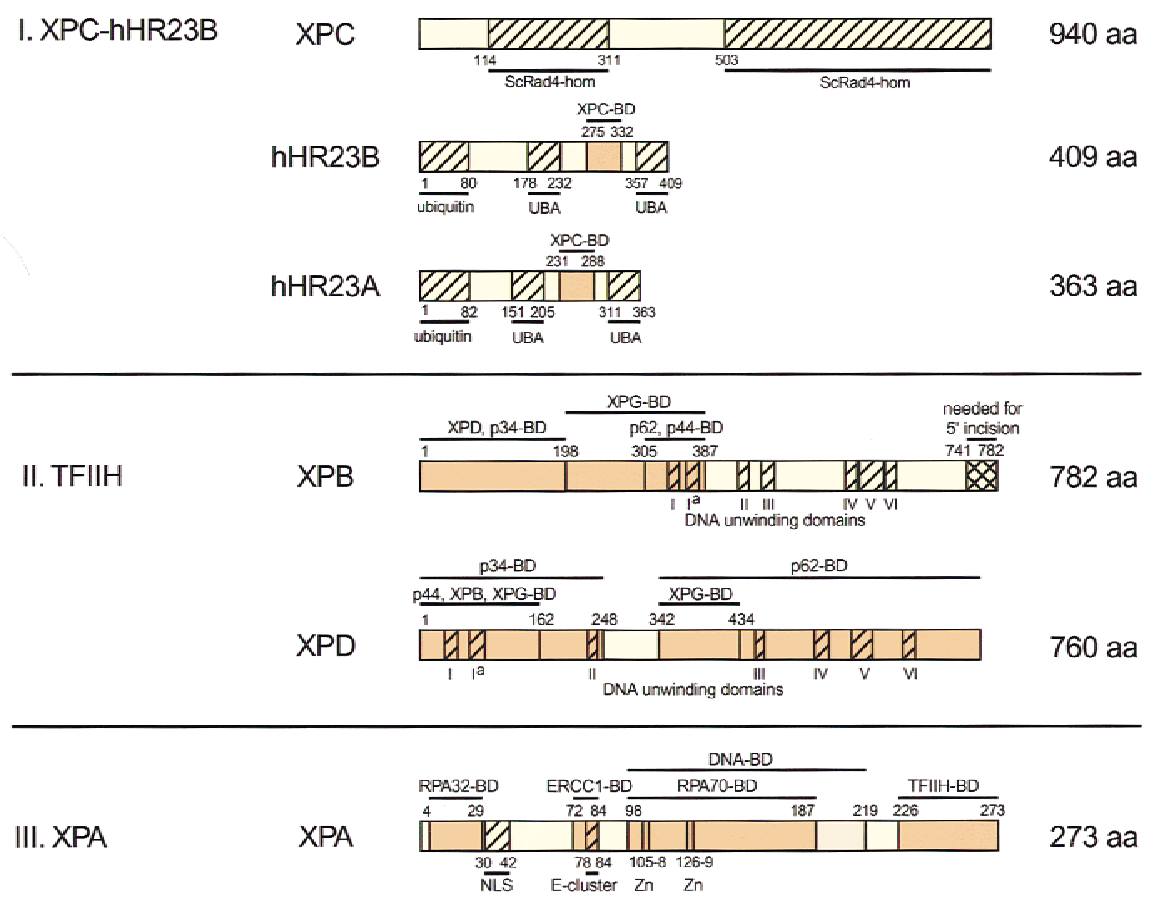

Figure 1. Functional domains in mammalian NER proteins. Schematic presentation of identified functional domains in NER proteins. DNA- and protein-interaction domains are indicated above (brown boxes) (BD) Binding domain; (putative) functional domains based on primary amino acid sequence are indicated below each schematic presentation (hatched boxes). (XPC-hHR23B) ScRad4-hom: Domains within XPC with (limited) homology to $S$. cerevisiae Rad4. Ubiquitin: Ubiquitin-like region. UBA: Ubiquitin-associated domain. (TFIIH) p34, p44, and p62 are other TFIIH subunits. (XPA) NLS: Nuclear localization signal. E-cluster: Glutamic acid-rich region. $\mathrm{Zn}: \mathrm{Zn}^{2+}$ finger. (RPA) SBD: Putative ssDNA-binding domain. (XPG) N, I, and C are regions conserved in the FEN-1 family of structure-specific endonucleases. (ERCC1-XPF) 2xHhH-motif: Double-HhH motif.

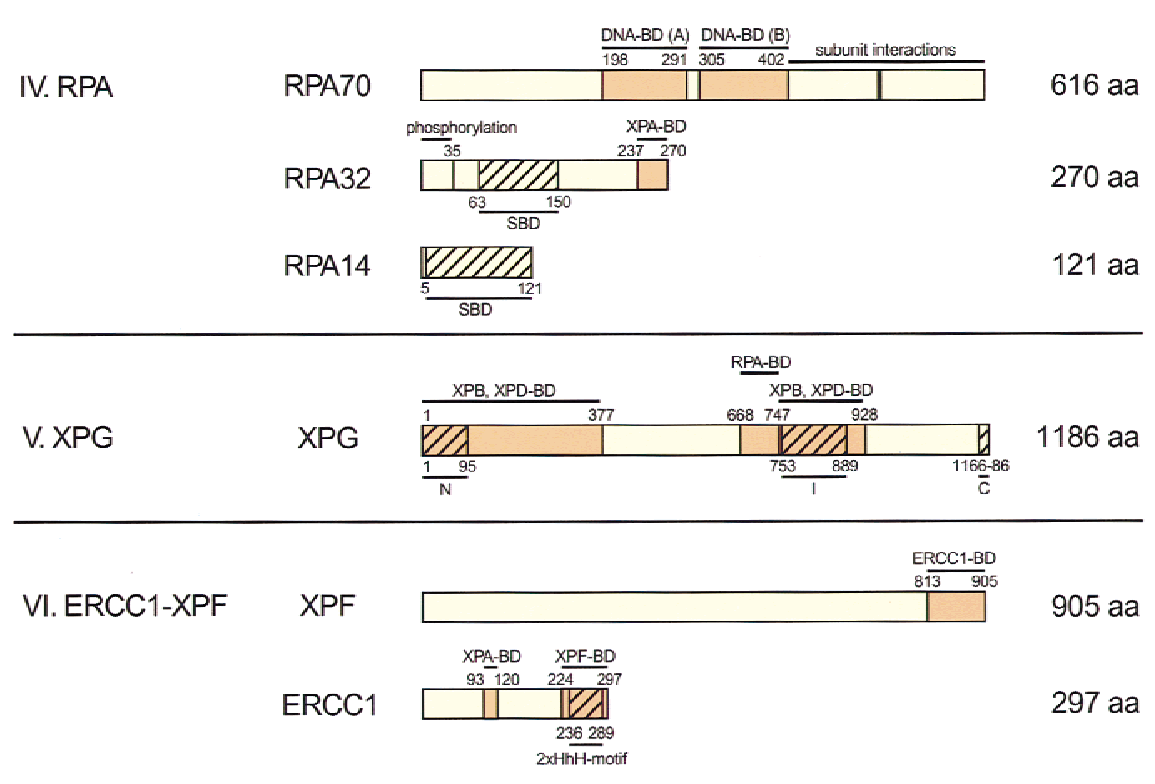

complexes (Table 2). XPC-hHR23B and XPC alone display a similar high affinity for both single-stranded (ss) and double-stranded (ds) DNA and a preference for UVdamaged DNA (Masutani et al. 1994; Shivji et al. 1994; Reardon et al. 1996a). XPC-hHR23B is absolutely required for dual incision as well as for open complex formation during GG-NER (Aboussekhra et al. 1995; Mu et al. 1995, 1997; Mu and Sancar 1997; Evans et al. 1997b). An artificial DNA substrate containing single-stranded bubbles across or $5^{\prime}$ of a lesion obviated the requirement of XPC-hHR23B (Mu and Sancar 1997). Furthermore, both the helicase complex TFIIH and XPC-hHR23B were essential for (limited) opening around a damage (Evans et al. 1997b). Also, XPC-hHR23B is dispensable for in vitro repair of an artificial cholesterol DNA adduct. Apparently, certain DNA structures alleviate the need for XPC-hHR23B (Mu et al. 1996). These data are all in line with a role for XPC-hHR23B in open complex formation and/or stabilization but do not exclude a role even earlier in the reaction.

Evidence for the latter was obtained recently by a series of experiments in which two damaged plasmids of different sizes were separately preincubated, one with purified XPC-hHR23B and the other with all other NER factors. After mixing, initial repair was found focused on the plasmid preincubated with XPC-hHR23B, demonstrating that XPC-hHR23B is the first factor in NER, working even before TFIIH, XPA, and RPA and capable 
Table 2. Physical interactions between NER proteins

\begin{tabular}{|c|c|c|c|c|}
\hline & TFIIH & RPA & XPG & ERCC1-XPF \\
\hline XPA & $\begin{array}{l}\text { PD } \\
\text { (Park et al. 1995a; } \\
\quad \text { Nocentini et al. 1997) }\end{array}$ & $\begin{array}{l}\text { PD, CP } \\
\text { (He et al. 1995; Li et al. } \\
\text { 1995b; Saijo et al. 1996; } \\
\text { Stigger et al. 1998) }\end{array}$ & & $\begin{array}{l}\mathrm{PD}, 2 \mathrm{H} \\
\text { (Li et al. 1994; 1995a; } \\
\quad \text { Park and Sancar 1994; } \\
\text { Saijo et al. 1996) }\end{array}$ \\
\hline XPC-hHR23B & $\begin{array}{l}\text { CP } \\
\text { (Drapkin et al. 1994) }\end{array}$ & & & \\
\hline TFIIH & & & $\begin{array}{l}\text { CP, IP } \\
\text { (Mu et al. 1995; } \\
\quad \text { Iyer et al. 1996) }\end{array}$ & \\
\hline RPA & & & $\begin{array}{l}\mathrm{PD}, \mathrm{XL} \\
\text { (He et al. 1995; } \\
\quad \text { de Laat et al. 1998b) }\end{array}$ & $\begin{array}{l}\mathrm{PD}, \mathrm{XL} \\
\text { (Bessho et al. 1997; } \\
\quad \text { de Laat et al. 1998b) }\end{array}$ \\
\hline
\end{tabular}

(PD) Pull-down experiments: (GST-, MBP-) affinity chromatography (techniques using large quantities of 'bait' protein). (CP) Copurification or coprecipitation from cell extracts. $(2 \mathrm{H})$ Dual hybrid system. (IP) (Immuno-) coprecipitation of in vitro-translated gene products (low protein concentrations). (XL) Glutaraldehyde cross-linked at DNA junctions. Relevant references are indicated.

of recruiting the remainder of the repair machinery to the lesion (Sugasawa et al. 1998). DNase I footprinting showed that XPC-hHR23B binds directly to DNA damage and changes the DNA conformation around the lesion (Sugasawa et al. 1998). Thus, XPC-hHR23B initiates GG-NER by sensing and binding lesions, locally distorting the DNA double helix and recruiting the other factors of the system.

\section{TFIIH}

TFIIH is a nine-subunit protein complex (Winkler et al. 1998) involved in initiation of RNA polymerase II (Pol II) transcription (Conaway and Conaway 1989; Feaver et al. 1991; Gerard et al. 1991; Flores et al. 1992), NER (Feaver et al. 1993; Schaeffer et al. 1993, 1994; Drapkin et al. 1994; van Vuuren et al. 1994; Vermeulen et al. 1994; Wang et al. 1994, 1995) and possibly in cell cycle regulation (Feaver et al. 1994; Roy et al. 1994a; Serizawa et al. 1995; Shiekhatter et al. 1995). In NER, TFIIH functions both in GG-NER and TC-NER. XP patients with mutations in XPB or XPD may also show manifestations typical of CS or TTD, indicating a central role of TFIIH in transcription-coupled repair (see below). TFIIH has multiple enzymatic activities. XPB and XPD exhibit DNAdependent ATPase and helicase functions; XPB can unwind DNA in a $3^{\prime} \rightarrow 5^{\prime}$ direction, and XPD in the opposite direction (Schaeffer et al. 1993, 1994; Roy et al 1994b). The cdk-activating kinase (CAK) subcomplex, comprising subunits Cdk7, cyclin $\mathrm{H}$, and Mat1, can phosphorylate several cyclin-dependent kinases (cdks), as well as the carboxy-terminal domain of the large subunit of RNA Pol II, activities relevant to cell cycle regulation and transcription initiation, respectively (Feaver et al.1991; Roy et al. 1994a). The p34 and p44 subunits of TFIIH contain $\mathrm{Zn}^{2+}$-finger motifs and putative DNAbinding capacity (Humbert et al. 1994). As yet, no functions have been assigned to the remaining p52 and p62 subunits (Fischer et al. 1992; Marinoni et al. 1997). Several subcomplexes of TFIIH exist in the cell. The core complex comprises p34, p44, p52, p62, and XPB. CAK is present both as a free heterotrimer and as a component of TFIIH, presumably by binding to XPB and XPD (Rossignol et al. 1997). XPD is found associated with both core TFIIH and the CAK complex (Serizawa et al. 1995; Shiekhatter et al. 1995; Svejstrup et al. 1995; Reardon et al. 1996b; Rossignol et al. 1997). CAK is required for RNA Pol II transcription initiation but is dispensable for in vitro NER (Sung et al. 1996; Wang et al. 1995; Mu et al. 1996).

Both in transcription initiation and in NER, TFIIH is needed for melting the DNA double helix (Holstege et al. 1996; Evans et al. 1997b; Mu et al. 1997). Permanganate footprinting studies on the adenovirus major late promoter showed that promoter melting, necessary to activate the RNA Pol II initiation complex, proceeds in three steps (Dvir et al. 1996; Holstege et al. 1996, 1997; Jiang et al. 1996; Yan and Gralla 1997). Initially, $11 \mathrm{bp}$ around the initiator site (from position -9 to +2 ) are melted. Melting and maintenance of this open complex require the ATPdependent helicases of TFIIH (Holstege et al. 1995, 1996; for review, see Okhuma 1997). Further opening to position +4 (13 bp unwound) occurs concomitant with the formation of the first RNA phosphodiester bonds and is also TFIIH dependent. Finally, progression to a 17-bp opened complex $(-9 /+8)$, which marks the transition to a productive RNA Pol II elongation complex, proceeds independent of TFIIH (Holstege et al. 1997). Thus, TFIIH is actively involved in creating and maintaining an 11- to 13-bp opening during transcription initiation. In NER, the full open complex spans 20-30 bp around the lesion. Footprinting studies on a site-specific lesion with cellfree extracts showed that TFIIH is also indispensable for repair opening. In the absence of ATP, repair unwinding is abolished (Evans et al. 1997a). Accordingly, an ATPase-inactivated mutant form of TFIIH fails to make an open complex (G. Winkler and J.H.J. Hoejimakers, unpubl.). Limited opening ( $<10 \mathrm{bp}$ ) was still observed in extracts lacking RPA, XPA, or XPG but was completely absent in extracts containing mutated XPB, XPD, and XPC protein (Evans et al. 1997b). Possibly, analogous to 
opening in transcription initiation, open complex formation in repair occurs in multiple steps and the helicase activity of TFIIH is restricted to initial opening only (discussed more extensively below).

Demarcation of the lesion through local DNA opening provides the ss- to dsDNA transitions required for cleavage by the two structure-specific NER nucleases XPG and ERCC1-XPF (see below). Studies with premelted DNA substrates containing a site-specific lesion revealed that DNA unwinding is not the only function of TFIIH in excision repair. Unlike what was found for transcription initiation, bubbles of 10 nucleotides at the $3^{\prime}$ and $5^{\prime}$ side, as well as one of 20 nucleotides spanning the lesion, all still require TFIIH for efficient further processing, indicating an additional, probably structural, role for TFIIH in repair (Mu and Sancar 1997). Consistent with this notion, a number of interactions with repair factors have been reported, including XPA and the aforementioned interactions with XPC (Bardwell et al. 1994; Drapkin et al. 1994; Park et al. 1995a; Nocentini et al. 1997) (Table 2). Direct in vitro interactions were also described between multiple subunits of TFIIH and XPG (Iyer et al.1996), consistent with the reported detection of XPG in partially purified TFIIH fractions (Mu et al. 1995). A mutant in the carboxy-terminal domain of XPB was shown to fully support DNA unwinding and allow 3 ' but not $5^{\prime}$ incision, suggesting that TFIIH facilitates the $5^{\prime}$ incision by ERCC1-XPF (Evans et al. 1997b). In vitro binding was also described between TFIIH and CSA, an interaction perhaps relevant for TCR (Henning et al. 1995). Clearly, in addition to unwinding, TFIIH has other engagements in NER.

\section{XPA}

The XPA gene product has a crucial role at an early stage of both TC-NER and GG-NER (Tanaka et al. 1990). It is a DNA-binding protein (Fig. 1) with a marked preference for damaged DNA (Robins et al. 1991; Jones and Wood 1993; Asahina et al. 1994). The $\mathrm{Zn}^{2+}$-finger containing minimal region required for DNA binding (Fig. 1) (Tanaka et al. 1990; Kuraoka et al. 1996; Morita et al. 1996; Buchko and Kennedy 1997) is essential for its function (Miyamoto et al. 1992; Asahina et al. 1994). The structure of this domain has been resolved recently (Buchko et al. 1998; Ikegami et al. 1998). Various NERspecific types of damage, including 6-4PPs and CPDs, are recognized by XPA and, in general, the affinity of XPA for a lesion correlates with the extent of helical distortion (Robins et al. 1991; Jones and Wood 1993; Asahina et al. 1994). It has been suggested that the single-strandedness of damaged sites may be the determinant for XPA recognition (Jones and Wood 1993). In addition, XPA maintains an intricate network of contacts with core repair factors (see Table 2). In vitro protein-protein interactions were reported with ERCC1 (Li et al. 1994a, 1995a; Park and Sancar 1994), XPF (weak interaction) (Bessho et al. 1997), the p32 and p70 subunits of RPA (He et al. 1995; Li et al. 1995b; Saijo et al. 1996; Ikegami et al. 1998; Stigger et al. 1998), and TFIIH (Park et al. 1995a;
Nocentini et al. 1997) (see Table 2; for mapped interaction domains in XPA, see Fig. 1). Also, in vitro binding was claimed for the Cockayne syndrome B (CSB) protein and the p34 subunit of basal transcription factor TFIIE (Park et al. 1995a; Selby and Sancar 1997). In view of its damage preference, XPA has long been considered the damage-sensing and repair-recruitment factor of NER. However, as XPC-hHR23B was shown recently to act first, the function of XPA has to be reconsidered. Given its affinity for damaged DNA and its ability to interact with many (core) repair factors, XPA is anticipated to verify NER lesions and to play a central role in positioning the repair machinery correctly around the injury.

\section{RPA}

RPA, originally identified as a factor required for in vitro SV40 DNA replication (Wobbe et al. 1987; Fairman and Stillman 1988; Wold and Kelly 1988) has additional roles in NER and recombination (Coverley et al. 1991; 1992; Longhese et al. 1994; for review, see Wold 1997). Human RPA (hRPA) is a ssDNA-binding protein composed of three subunits of 70,32 , and $14 \mathrm{kD}$ (see Fig. 1). Its apparent ssDNA association constant of $10^{9}-10^{11} / \mathrm{M}$ is at least three orders of magnitude higher than to dsDNA (Kim et al. 1992, 1994). Binding of an RPA molecule to ssDNA involves the 70-kD subunit (Wold et al. 1989; Kenny et al. 1990; Gomes and Wold 1996; Kim et al. 1996), but single-stranded binding domains are also present in the $32-\mathrm{kD}$ and perhaps in the $14-\mathrm{kD}$ subunit (Philipova et al. 1996; Bochkarev et al. 1997, 1998; Brill and Bastin-Shanower 1998). Two binding modes have been identified; RPA interacts with a minimal region of 8-10 nucleotides (Blackwell and Borowiec 1994) that is thought to precede the almost 100-fold more stable 30nucleotide binding mode (Kim et al. 1992, 1994; Blackwell et al. 1996). In yeast, binding modes involving larger DNA stretches (90-100 nucleotides) have been reported (Alani et al. 1992). Recently, we showed that RPA binds ssDNA with a defined polarity and that initial DNA binding occurs at the 5'-oriented site of RPA /de Laat et al. 1998b). Possibly, transition to the full 30-nucleotide binding form involves stretching of the RPA molecule along the DNA in the 3' direction. Cooperativity of RPA binding to ssDNA is considered low, but human RPA is still 10-20 times more likely to bind adjacent to an already bound RPA molecule than to naked DNA (Kim et al. 1994, 1995). In RPA-dependent DNA-metabolizing processes, complementary DNA strands are separated at a certain stage and action is required along ssDNA intermediates. By binding to ssDNA, RPA is thought to stabilize such intermediates and remove secondary structures.

In NER, full opening around the lesion requires RPA (Evans et al. 1997b; Mu et al. 1997), which probably binds to the undamaged DNA strand (de Laat et al. $1998 b)$. The size of the fully opened repair intermediate is $\sim 30$ nucleotides, which corresponds to the size of the optimal DNA-binding region of a single RPA heterotrimer. RPA may not only stabilize a fully open repair com- 
plex, but also facilitate its creation. RPA is also crucial for coordinating the NER nucleases. Interactions were demonstrated with both XPG and ERCC1 (excision repair cross complementation group $\underline{1})-\mathrm{XPF}$ (He et al. 1995; Matsunaga et al. 1996; Bessho et al. 1997; de Laat et al. 1998b) (Table 2), and recently it was found that the defined DNA-binding orientation of RPA is particularly relevant for these interactions. Bound to the undamaged strand, the 3 '-oriented side of RPA binds ERCC1-XPF, whereas the $5^{\prime}$-oriented side binds XPG. RPA confers strand specificity to ERCC1-XPF by strongly stimulating incisions in the damaged strand and inhibiting cuts in the undamaged strand (de Laat et al. 1998b). RPA and XPA bind cooperatively to damaged DNA (He et al. 1995; Saijo et al.1996). RPA itself was also found to have affinity for damaged DNA (Clugston et al. 1992; He et al. 1995; Burns et al. 1996), which led to the suggestion that this factor is involved in DNA damage recognition. However, because RPA is anticipated to bind the undamaged strand during NER (de Laat et al. 1998b), RPA probably does not recognize the lesion per se but, rather, has affinity for single-stranded regions exposed by lesion-induced helical distortion. Consistent with this notion, RPA was reported to bind to single-stranded bubbles as small as 4 nucleotides (Wold 1997).

On the basis of its dual involvement in replication and repair, it can be anticipated that RPA not only acts at preincision stages but also during DNA repair synthesis. DNA polymerase $\delta$ and $\epsilon(\mathrm{Pol} \delta$ and Pol $\epsilon)$ have been implicated in repair synthesis, and both can be stimulated by RPA. Stimulation was not dependent on specific protein-protein interactions, as other SSBs could replace RPA (Kenny et al. 1989, 1990; Tsurimoto et al. 1989; Lee et al. 1991). However, genetic evidence in yeast suggests that RPA and Pol $\delta$ do have a direct interaction (Longhese et al. 1994). Possibly, RPA remains bound to the undamaged strand after excision, thereby facilitating gap-filling DNA repair synthesis, which initiates at the $5^{\prime}$ incision site.

Finally, the p32 subunit of RPA was found to be phosphorylated in a cell cycle-dependent manner and in response to DNA damage (Din et al. 1990; Fang and Newport 1993; Liu and Weaver 1993; Carty et al. 1994). Whether the phosphorylation status of RPA has any effect on the efficiency of NER in vivo remains to be established (Pan et al. 1995; Ariza et al. 1996).

\section{XPG}

The XPG gene encodes a structure-specific endonuclease, which cleaves a variety of artificial DNA substrates, including bubbles, splayed arms and stem-loops (O'Donovan and Wood 1993; Scherly et al. 1993; O'Donovan et al 1994; Cloud et al. 1995; Evans et al. 1997a). In addition, the XPG homolog of $S$. cerevisiae, Rad2 (Table 1) can remove single-stranded arms protruding from duplex DNA in so-called flap substrates (Habraken et al. 1995). XPG-mediated incisions always occur in one strand of duplex DNA at the 3 ' side of a junction with ssDNA. One single-stranded arm, protruding in either the $3^{\prime}$ or $5^{\prime}$ direction, is necessary and sufficient for correct positioning of XPG incisions /de Laat et al. 1998a). Consistent with this cleavage polarity, XPG makes the 3' incision during NER (O'Donovan et al. 1994) at the border of the open DNA intermediate (Evans et al. 1997a). In bubble substrates, XPG requires a minimal opening of 5 nucleotides for incisions (Evans et al. 1997a). The XPG protein is a member of the FEN-1 family of structure-specific endonucleases, which all cut with similar polarity at junctions of duplex and unpaired DNA (for review, see Lieber 1997). XPG shares three regions of homology (Fig. 1) with the founder of this family, FEN-1, which is implicated in the processing of Okazaki fragments during replication (Waga et al. 1994b; Rumbaugh et al. 1997), the completion of a subpathway of BER (Klungland and Lindahl 1997), and possibly DNA end joining of dsDNA breaks (Lieber 1997). Three aspartic acid and one glutamic acid residue are absolutely essential for FEN-1 cleavage (Shen et al. 1996, 1997). One of these, Asp-181 in FEN-1, is required for cleaving but not for binding DNA. Substitution of the corresponding residue in XPG, Asp-812 by alanine (D812A) induced a selective defect in its nuclease activity (Mu et al. 1997; Wakasugi et al. 1997).

The XPG-mediated 3' incision precedes the $5^{\prime}$ incision made by ERCC1-XPF ( $\mathrm{Mu}$ et al. 1996). Interestingly, XPG is not only required for the $3^{\prime}$ incision but also for full open-complex formation, indicating a structural role in the core NER reaction (Evans et al. 1997b; Mu et al. 1997). Evidence for such a role was provided with the D812A active-site mutant of XPG, which had to be present to detect ERCC1-XPF-mediated 5' incisions in an in vitro-reconstituted repair assay with purified factors $(\mathrm{Mu}$ et al. 1997; Wakasugi et al. 1997). Furthermore, this same XPG mutant was found to stabilize a preincision complex containing XPC-hHR23B, TFIIH, XPA, and RPA (Mu et al. 1997). Apparently, independent of its cleavage activity, XPG has a structural function in the assembly of the NER DNA-protein complex. The reported interactions of XPG with TFIIH and RPA may be relevant in this respect (Bardwell et al. 1994; He et al. 1995; Iyer et al. 1996; de Laat et al. 1998b). Similar to FEN-1, XPG was found to interact with proliferating cell nuclear antigen (PCNA) (Gary et al. 1997), a factor involved in DNA repair synthesis but dispensable for the incision stage of NER (Shivji et al. 1992). Whereas PCNA stimulates FEN-1 nuclease activity (Wu et al. 1996), no effect was found when PCNA was added to XPG nuclease assays (Evans et al. 1997a). Perhaps, this interaction allows cross talk between the incision and gap-filling stages of NER. An in vitro interaction was also observed with CSB (Iyer et al. 1996), possibly relevant to the mechanism that underlies transcription-coupled repair. Because various XP-G patients show CS features combined with XP manifestations, XPG, like TFIIH, is anticipated to be a key factor in coupling various repair processes to transcription.

\section{ERCC1-XPF}

The gene products of ERCC1 (33 kD; van Duin et al. 1986) and XPF (103 kD; Brookman et al. 1996; Sijbers et 
al. 1996a) form a stable complex in vivo and in vitro (Biggerstaff et al. 1993; van Vuuren et al. 1993; Park et al. 1995b; Sijbers et al. 1996a; de Laat et al. 1998c), involving amino acid stretches in the carboxyl terminus of both ERCC1 and XPF (de Laat et al. 1998c). Stability of the individual components in the cell is dependent on heterodimer formation (Sijbers et al. 1996b; Yagi et al. 1997). UV-sensitive Chinese hamster cells defective in either ERCC1 or XPF display also a unique, extreme sensitivity to interstrand cross-linking agents (Busch et al. 1989, 1997; Collins 1993). Removal of such cross-links probably involves recombination. Consistent with this idea, the homologous complex in S. cerevisiae, Rad10Rad1 (Table 1) is required for a specific mitotic recombination pathway called single-strand annealing (SSA) (Fishman-Lobell and Haber 1992), possibly via interactions with mismatch repair proteins (Paques and Haber 1997; Sugawara et al. 1997; Bertrand et al. 1998; BhuiKaur et al. 1998). Also, its Schizosaccharomyces pombe counterpart Swi10-Rad16 is involved in the recombinational events that underlie mating-type switching (Gutz and Schmidt 1985; Rodel et al. 1992, 1997).

The ERCC1-XPF complex is a structure-specific endonuclease (Sijbers et al. 1996a). Like its yeast homolog Rad1-Rad10, ERCC1-XPF incises a variety of DNA substrates, including bubbles, stem-loops, splayed arms, and flaps (Sijbers et al. 1996a; Bessho et al. 1997; de Laat et al. 1998a), with the latter possibly representing recombination intermediates. A minimal loop size of 4-8 nucleotides is required to detect ERCC1-XPF incisions (de Laat et al. 1998a). Incisions are always made in one strand of the duplex at the 5' side of the junction with ssDNA (Sijbers et al. 1996a; de Laat et al. 1998a). One single-stranded arm protruding in either the $3^{\prime}$ or $5^{\prime}$ direction is necessary and sufficient to correctly position ERCC1-XPF incisions at a DNA junction (de Laat et al. 1998a). In NER, ERCC1-XPF makes the 5' incision, consistent with its cleavage polarity (Matsunaga et al. 1995; Sijbers et al. 1996a).

A hint that ERCC1 may be the subunit catalyzing cleavage comes from the presence of a double helix-hairpin-helix $(\mathrm{HhH})$ motif in its carboxyl terminus (Sijbers et al. 1996b). HhH motifs are shared by other structurespecific endonucleases and have been implicated in DNA binding (Doherty et al. 1996). Deletion of the homologous double $\mathrm{HhH}$ motif in the carboxyl terminus of the E. coli NER protein UvrC disrupts 5' incisions without affecting 3' cleavage (Moolenaar et al. 1998). Possibly, this DNA-binding domain positions the catalytic cleavage site for $5^{\prime}$ incision. Intriguingly, recognizable $\mathrm{HhH}$ motifs are not apparent in the yeast homolog of ERCC1 Rad10.

The 5' incision by ERCC1-XPF follows the XPG-mediated 3' incision in NER (Mu et al. 1996). ERCC1-XPF can be omitted for full open complex formation and $3^{\prime}$ incision in vitro and can be added to a preformed incision complex, containing all other factors, to make the 5' incision (Mu et al. 1996, 1997; Evans et al. 1997b). Thus, unlike XPG, ERCC1-XPF does not appear to have an architectural function in the NER protein-DNA com- plex. Several protein interactions have been reported, that may account for positioning of ERCC1-XPF during NER. XPA interacts with the complex (Table 2) (Li et al. 1994a, 1995a; Park and Sancar 1994; Saijo et al. 1996), mainly via ERCC1 (Fig. 1), although a weak affinity for XPF also has been reported (Bessho et al. 1997). RPA and ERCC1 likely bind sequentially to XPA (Saijo et al. 1996). RPA also interacts with ERCC1-XPF (Table 2), presumably via XPF (Matsunaga et al. 1996; Bessho et al. 1997). This interaction seems particularly important for positioning the nuclease. Bound to ssDNA, the $3^{\prime}$ oriented side of RPA interacts with ERCC1-XPF and strongly stimulates its nuclease activity, whereas the $5^{\prime}$ oriented side of RPA does not interact with the complex and blocks ERCC1-XPF-mediated incisions /de Laat et al. 1998b).

\section{XPE}

$\mathrm{XPE}$ is dispensable for NER in vitro. However, in vivo it is required, as XP-E patients exhibit XP-like skin abnormalities and reduced repair synthesis (Bootsma et al. 1997). The defect in XP-E cells is not assigned unambiguously yet: a unique candidate for the XPE gene is still lacking. Some but not all XP-E patients lack a functional damaged DNA-binding (DDB) factor (Chu and Chang 1988; Hirschfeld et al. 1990; Kataoka and Fujiwara 1991; Keeney et al. 1992, 1994; Nichols et al. 1996). DDB is a heterodimeric protein complex with 127 - and 48-kD subunits and with affinity for certain types of DNA lesions (Hwang and Chu 1993; Keeney et al. 1993; Reardon et al. 1993), hinting at a function in damage recognition in NER. Some, but not all, patients carry a mutation in the gene for the small subunit (Nichols et al. 1996), which is under damage-inducible control by p53 (Hwang et al. 1999|. This explains the partial defect in GG-NER in p53-/- cells (Ford and Hanawalt 1997), supporting the idea that DDB facilitates the identification of lesions that are poorly recognized by the XPC-hHR23B complex, such as UV-induced CPD dimers (Hwang et al. 1999).

\section{DNA repair synthesis}

The incision and DNA synthesis stages of NER can be separated in vitro, and the only factor in common is RPA, which may remain bound to the undamaged strand to facilitate replication. In vitro studies with antibodies and chemical inhibitors revealed that both DNA Pol $\delta$ and Pol $\epsilon$ ) function in NER DNA synthesis (Dresler and Frattini 1986; Nishida et al. 1988; Hunting et al. 1991; Coverley et al. 1992; ). A similar observation was made in vivo in yeast (Budd and Campbell 1995), but the relative contribution of each remains to be determined. The requirement of PCNA is consistent with repair synthesis by these polymerases (Shivji et al. 1992), as it serves as a processivity factor for both, in conjunction with replication factor C (RF-C). The combination of RPA, PCNA, RF-C (five subunits) and either Pol $\delta$ or Pol $\epsilon$ was sufficient for repair synthesis in vitro (Shivji et al. 1995). 
DNA synthesis by Pol $\delta$ and Pol $\epsilon$ and their cofactors PCNA and RF-C has been studied extensively (for reviews and original references, see Budd and Campbell 1997; Hindges and Hübscher 1997; Jonsson and Hübscher 1997; Wood and Shivji 1997). Briefly, RF-C preferentially binds to 3' termini of DNA primers and facilitates the loading of PCNA, which forms a homotrimeric ring-shaped clamp that can track along duplex DNA. This complex serves as a docking platform for both Pol $\delta$ and Pol $\epsilon$, which upon binding form holoenzymes with the cofactors that efficiently can replicate ssDNA.

PCNA might serve as a mediator between cell cycle control and DNA repair. It interacts with p21, a cdk inhibitor that is up-regulated in a p53-dependent manner upon DNA damage (Waga et al. 1994a). This interaction inhibits DNA replication but does not affect DNA repair, which may contribute to the induction of replicational arrest to allow repair and prevent mutagenesis $(\mathrm{Li}$ et al. 1994b).

The final step in NER is ligation of the $5^{\prime}$ end of the newly synthesized patch to the original sequence. This step is probably carried out by DNA ligase I. Interestingly, a single case of DNA ligase I deficiency in humans has been described. This patient not only suffered from symptoms probably arising from (mild) defects in semiconservative replication but also showed increased sensitivity to several DNA-damaging agents, including UV light (Barnes et al. 1992; Prigent et al. 1994). (For a review on mammalian DNA ligases, see Tomkinson and Levin 1997.)

\section{Biochemical dissection of NER}

Eukaryotic NER removes damage as part of a 24- to 32nucleotide oligomer (Huang et al. 1992; Moggs et al. 1996), depending on the type of damage and the sequence context. Reconstitution of the NER reaction with purified proteins allowed the definition of a minimal set of proteins required for the entire GG-NER reaction (Aboussekhra et al. 1995; Mu et al. 1995, 1996). The repair synthesis stage merely involves general replication factors, and their action has been discussed above. Here, we will focus on the crucial events prior to repair synthesis. Recent studies on damage recognition, open complex formation and nuclease positioning, together with data obtained from genetic and cell biological studies, have allowed a detailed interpretation of the individual steps that lead to dual incision. All these events are composed into a molecular model shown in Figure 2.

\section{Damage sensing in GG-NER and TC-NER}

As discussed above, the XPC-hHR23B complex is the first NER factor to detect a lesion and recruit the rest of the repair machinery to the damaged site in GG-NER (Sugasawa et al. 1998). The complex has affinity for a variety of NER lesions including UV-induced injury and chemical damage, such as cisplatin and N-acetyl-acetoxyaminofluorene (AAF) adducts. DNase I footprinting assays revealed specific binding to a 6-4PP (Sugasawa et al. 1998). Probably, XPC is the subunit responsible for discerning 'right from wrong' in DNA, but at this moment it is unclear how this protein senses the wide range of structurally unrelated lesions in a vast excess of normal DNA. For some types of damages, such as the poorly repaired CPD lesions, other proteins like the UV-DDB protein complex may assist in lesion detection (see above). Furthermore, XPA, as another NER factor with preferential affinity for several types of injury, likely acts as a damage verifier in subsequent stages in the NER reaction (Sugasawa et al. 1998).

How does XPC-hHR23B recruit other repair factors in GG-NER? Evans et al. (1997b) reported that XPC and TFIIH are the only factors absolutely required for helix distortion around the lesion. This may be sufficient for the rest of the repair machinery to act, as locally premelted lesions are repaired efficiently in the absence of XPC-hHR23B (Mu and Sancar 1997; Mu et al. 1997). Thus, XPC-hHR23B may slightly increase single strandedness at a damaged site to facilitate entering of TFIIH and other repair factors. Perhaps a similar helical distortion underlies the observation that artificial cholesterol lesions bypass the need for XPC-hHR23B (Mu et al. 1996). In addition, XPC-hHR23B may recruit other repair factors through specific protein-protein interactions. The complex has only been reported to interact (weakly) with TFIIH (Drapkin et al. 1994). In yeast, Rad4 (XPC)-TFIIH, Rad23-TFIIH, and Rad23-Rad14 (XPA) interactions have been claimed (Bardwell et al. 1994; Guzder et al. 1995).

XPC-hHR23B is not involved in transcription-coupled repair. This suggests that other factors perform damage detection in TC-NER and provide a DNA substrate that can be processed by the rest of the repair machinery. Elongating RNA Pol II is blocked by many lesions in the transcribed strand. This makes it an efficient damage sensor (Donahue et al. 1994; Hanawalt and Mellon 1993). The transcription bubble present at the lesion can serve as a substrate for XPC-hHR23B-independent repair (Hanawalt and Mellon 1993; Mu and Sancar 1997; Mu et al. 1997). In vivo XPC-hHR23B competes with elongating Pol II for detecting lesions in transcribed strands; depending on their damage detection rates and the intensity of transcription, lesions will be repaired by either GG-NER or TC-NER. In agreement with this model, removal of 6-4PPs by GG-NER is very fast (Mitchell and Nairn 1989), and TC-NER does not contribute significantly to the repair rate (van Hoffen et al. 1995). On the other hand, repair of CPDs by GG-NER is much slower. Consequently, TC-NER accounts for the fast repair of these lesions from actively transcribed strands (Mellon et al. 1987; Mellon and Hanawalt 1989). On the other side of the spectrum, lesions are to be expected that fully depend on TC-NER, due to failing recognition by GGNER. Such a condition is fulfilled by DNA damage caused by the mushroom drug illudin S (N.G.J. Jaspers, unpubl.). In comparison to UV, illudin-induced NER levels are quite low, even in normal cells, and require the presence of al TC-NER factors, including CSA and CSB, but are independent of XPC and XPE. 
Figure 2. Molecular model for the incision stage of NER. (I) XPC-hHR23B (C) senses DNA helixdistorting NER lesions in global genome NER (GG-NER) leading to conformational alterations of the DNA. In transcription-coupled repair (TCNER) lesions are detected by elongating RNA Pol II blocked by, e.g., CPDs (NER lesions) and thymine glycols (non-NER lesion). (II) (Left) XPC-hHR23B at lesion attracts TFIIH [and possibly XPG (G)]. TFIIH creates a 10- to 20-nucleotide opened DNA complex around the lesion by virtue of its helicases $\mathrm{XPB}$ and XPD; this step requires ATP. XPChHR23B may be released at this or one of the subsequent stages. (Right) CSA, CSB, TFIIH, XPG, and possibly other cofactors displace the stalled Pol II from the lesion, which now becomes accessible for further repair processing; depending on the type of lesion, repair is completed by NER or by other repair pathways. (III) XPA (A) and RPA stabilize the 10- to 20-nucleotide opening and position other factors. XPA binds to the damaged nucleotides, RPA to the undamaged DNA strand. Possibly, RPA binds in its 8- to 10-nucleotide binding mode and transition to the 30-nucleotide binding mode (RPA stretching) plays an important role in full open complex formation. XPG stabilizes the fully opened complex. (IV) XPG, positioned by TFIIH and RPA, makes the 3 ' incision. ERCC1-XPF (F), positioned by RPA and XPA, makes the second incision $5^{\prime}$ of the lesion. $(V)$ Dual incision is followed by gap-filling DNA synthesis and ligation. Drawn contacts between molecules reflect reported protein-protein interactions.

\section{Open complex formation}

Once lesions have been traced, an open DNA complex is formed by the coordinated activities of XPC-hHR23B, TFIIH, XPA, and RPA. The ATP-dependent helicases of TFIIH have a key role in this process, whereas XPG seems to stabilize the complex (Evans et al. 1997a,b; Mu et al. 1997; Wakasugi et al. 1997). The fully opened intermediate is formed asymmetrically around the lesion, skewed to the $5^{\prime}$ site. Permanganate footprinting studies on damaged DNA substrates in the presence of repairdeficient cell extracts suggest that XPC-hHR23B and TFIIH together are required for an initial opening of $<10$ nucleotides, and that addition of XPA, RPA, and XPG is needed to obtain full opening of $\sim 25$ nucleotides (Evans et al. 1997a,b). Other studies using similar techniques but with purified factors suggested that all four preincision factors are necessary and sufficient to obtain an intermediate opening of 10-20 nucleotides positioned rather symmetrically around the lesion; full opening was
GG-NER

NER lesions

(eg. UV damage)

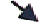

4

Genome overall

XPC-hHR23B

$\downarrow$
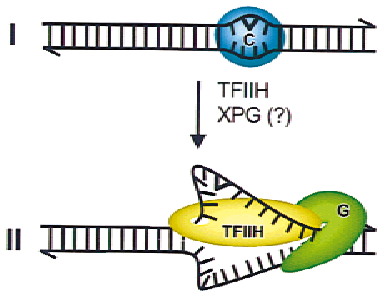

TC-NER

Elongating Pol II blocking lesions (eg. UV-and oxidative damage) $\Delta$

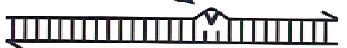

Transcribed DNA
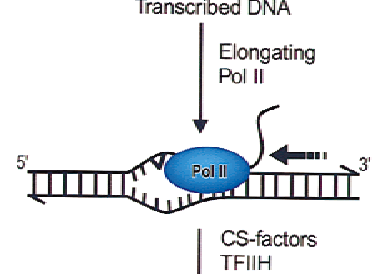

TFIIH

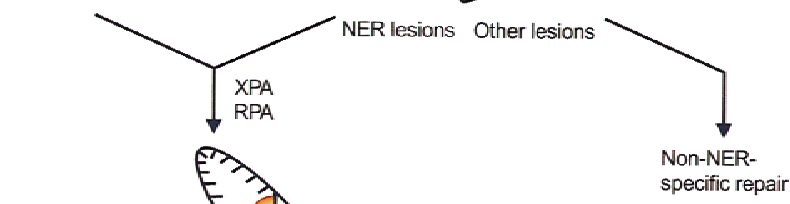

III

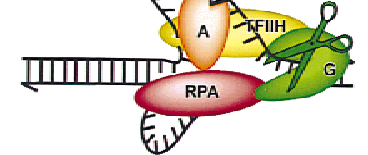

ERCC1-XPF

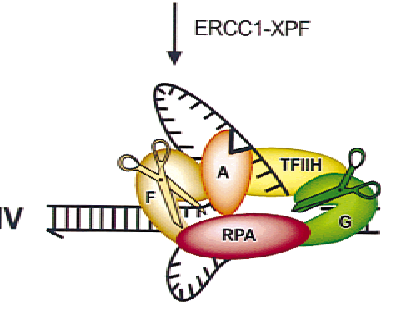

$\mid \begin{aligned} & \text { Replication } \\ & \text { factors }\end{aligned}$

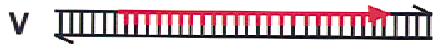

only observed in conjunction with dual incision (Mu et al. 1997). These discrepancies may be due to differences in experimental procedures and/or DNA substrates or the limited sensitivity of permanganate acting only on thymine residues. Both studies, however, indicate a twostep unwinding model with an ATP-dependent, TFIIHmediated initial opening and a subsequent extension of the open complex 5' away from the lesion. Such a mechanism would be analogous to TFIIH-dependent promoter opening in transcription initiation (Holstege et al. 1996, 1997; Yan and Gralla 1997).

How do the various factors contribute to opening? A number of possibilities exist: (1) TFIIH harbors two oppositely directed, ATP-dependent helicase subunits XРB and XPD, and is the motor driving the strand separation. In transcription initiation, TFIIH-dependent opening spans initially 10-15 nucleotides (Holstege et al. 1996, 1997), which is similar to the size of initial opening in repair (Evans et al. 1997b; Mu et al. 1997). The fact that opening is restricted to 10 to 20 nucleotides may reflect 
an intrinsic limitation of TFIIH-mediated strand separation. In addition to unwinding, TFIIH may have a structural role in the preincision complex, as premelted lesions still require TFIIH for repair (Mu and Sancar 1997; Mu et al. 1997). (2) XPA might account for correct positioning of the opened DNA-protein preincision complex, because it can bind the DNA adduct in an open conformation and interacts with both TFIIH and RPA (see above). (3) RPA may stabilize the unwound DNA intermediate. Most likely it binds and protects the undamaged strand in repair (de Laat et al. 1998b), and it is tempting to implicate the ssDNA-binding characteristics of RPA in the creation of a full open repair complex. The $5^{\prime}$-oriented side of RPA contains a strong DNAbinding domain that accounts for initial association to 8to 10-nucleotide DNA regions (Blackwell and Borowiec 1994; Blackwell et al. 1996; de Laat et al. 1998b). Stable binding of RPA to DNA requires $~ 30$-nucleotide singlestranded regions (Kim et al. 1992; Blackwell and Borowiec 1994). Interestingly, initial opening in NER exposes $\sim 10-20$ nucleotides of the undamaged strand, thus creating an ideal docking site for the $5^{\prime}$-oriented side of RPA. We propose that subsequent RPA stretching in the 3' direction contributes to the formation of a fully opened complex, which matches the observed $\sim 30$-nucleotide open intermediate.

It is not known whether repair in vivo involves sequential assembly of individual factors or loading of a complete 'repairosome' onto a DNA lesion. In either case, the repair factors are likely to act in a defined order. It is interesting to note that in mammals only TFIIH has been reported to interact with the repair recruitment factor XPC-hHR23B (Drapkin et al. 1994). Because XPC and TFIIH are the only factors indispensable for any conformational change around a lesion, Evans et al. (1997b) proposed that XPC-hHR23B and TFIIH may accomplish initial repair opening. Thus, TFIIH may well be the second factor acting at the site of damage. This would imply that TFIIH facilitates the recruitment of XPA to the lesion, rather than the other way around (Park et al. 1995a; Nocentini et al. 1997). Although merely speculation, TFIIH also seems an attractive candidate to be the first 'repair' factor acting in the XPC-hHR23B-independent TC-NER pathway, given its intimate link with both transcription and repair. Also, TFIIH has been shown to enter early stalled Pol II complexes (Dvir et al. 1997).

\section{Dual repair incision}

Following lesion demarcation, the actual incisions are made by the structure-specific endonucleases XPG $\left(3^{\prime}\right.$ incision) and ERCC1-XPF (5' incision) (O'Donovan et al. 1994; Matsunaga et al. 1995; Sijbers et al. 1996a). Incisions are made asymmetrically around the lesion, with the 3' incision 2-8 nucleotides and the 5' incision 15-24 nucleotides away from the lesion, corresponding to the borders of the open complex (Huang et al. 1992; Moggs et al. 1996; Evans et al. 1997a). The exact incision positions seem to depend in part on the type of lesion (Matsunaga et al. 1995; Moggs et al. 1996). Although incisions occur near synchronously, consensus exists that the $3^{\prime}$ incision precedes the 5' incision ( $\mathrm{Mu}$ et al. 1996). In agreement with this order, XPG-mediated cleavage can be detected in the absence of ERCC1-XPF, but ERCC1-XPF incision activity requires the structural presence, but not the catalytic activity, of XPG (Mu et al. 1997; Wakasugi et al. 1997). Also, limited opening of 10-20 nucleotides is sufficient for XPG cleavage, whereas ERCC1-XPF cutting in NER requires full opening of 25-30 nucleotides (Evans et al. 1997b; Mu et al. 1996, 1997).

In principle, XPG and ERCC1-XPF are able to cut both strands of an opened DNA intermediate (O'Donovan et al. 1994; Sijbers et al. 1996a), but during repair the nucleases are directed to the damaged strand only. RPA appears to have a crucial role in nuclease positioning. Each side of this molecule, when oriented on ssDNA, interacts with a distinct nuclease. In fact, bound to the undamaged strand, RPA alone is sufficient to confer strand specificity to ERCC1-XPF-mediated incisions (de Laat et al. 1998b). XPA's interaction with both RPA and ERCC1-XPF may facilitate or stabilize the positioning of ERCC1-XPF and RPA onto the damaged strand (Li et al. 1994a, 1995a,b; Park and Sancar 1994; Saijo et al. 1996). RPA presumably contributes, but is not sufficient, to confer strand specificity to XPG. Despite a specific interaction with RPA, XPG incisions in the damaged strand are not stimulated by RPA, nor does RPA inhibit XPG incisions in the undamaged strand (de Laat et al. 1998b). TFIIH is an attractive candidate to be involved in XPG positioning. Physical interaction between these two NER components has been reported both in yeast and in man (Bardwell et al. 1994; Habraken et al. 1996; Iyer et al. 1996). In addition, strikingly similar CS features are associated with mutations in both factors. XPC-hHR23B, on the other hand, seems not directly involved in coordinating either of the nucleases, as this factor probably leaves the repair complex prior to incisions (Wakasugi and Sancar 1998).

The $5^{\prime}$ incision by ERCC1-XPF, which completes the incision stage, leaves a hydroxyl (-OH)-group at the $3^{\prime}$ terminus of the primer strand and no additional modifications are required to start DNA synthesis at this side of the gap (Sijbers et al. 1996a). In vitro, the oligonucleotide containing the damage can be released by the NER incision factors in the absence of DNA repair synthesis (Mu et al. 1996, 1997). Probably, most NER proteins leave prior to repair synthesis. However, RPA is required for gap-filling DNA synthesis to protect the template strand against nucleases and/or to facilitate DNA replication. Replication does not result in strand displacement beyond the patch but, rather, stops at the $3^{\prime}$ cleavage site.

\section{Coupling of transcription to different repair pathways; a central role for TFIIH and XPG}

Transcription-coupled repair is well documented for elongation-stalling NER lesions for which GG-NER is too slow. However, evidence is accumulating that also transcription-blocking damage targeted by other repair 
systems is subject to preferential repair, including oxidative damage such as thymine glycols (Leadon and Lawrence 1992; Leadon and Cooper 1993; Cooper et al. 1997). Thus, all lesions that interfere with transcription elongation may well be a substrate for transcriptioncoupled repair (see also Tijsterman et al. 1997; Tu et al. 1997). Cells from XP-A, XP-F, and XP-G patients, which display only XP features, are defective in transcriptioncoupled repair of typical NER lesions, but appear normal in transcription-coupled repair of oxidative damage removed by other repair pathways (Cooper et al. 1997). In contrast, cells from CS-A and CS-B patients are defective in transcription-coupled repair of both CPDs and at least some types of oxidative damage lesions /Venema et al. 1990b; Leadon and Lawrence 1992; Leadon and Cooper 1993; van Hoffen et al. 1993; Cooper et al. 1997). This suggests that CS is linked to a more general transcription-coupled repair defect not limited to TC-NER. Thus, it seems that more than one repair pathway utilizes the damage-sensing capacity of elongating Pol II. It should be noted also that mismatch repair proteins have been implicated in the coupling between transcription and repair (Mellon et al. 1996; Leadon and Avrutskaya 1997, 1998).

Interestingly, a subclass of XP-B, XP-D, and XP-G patients displays CS features in combination with XP. Cells from these individuals appear deficient in the transcription-coupled removal of both UV-induced lesions and oxidative damage (Cooper et al. 1997), consistent with the idea that the repair defect in CS involves transcription coupling to multiple repair systems. This distinguishes the factors involved, TFIIH and XPG, from the other core NER proteins and links them with coupling of transcription to other repair pathways as well. One possible explanation is that these factors play a role in a stage of transcription-coupled repair common to different repair processes. Hanawalt and Mellon (1993) argued that for TC-NER, the stalled Pol II complex has to retract or dissociate to allow access of repair proteins to the lesion. Assuming that defects in this process underlie the extensive and perhaps even complete defect in transcription-repair coupling observed in CS cells, we propose that TFIIH and XPG, like CSA and CSB, function in the displacement of Pol II from the damaged site. CSB was recently found to be associated to Pol II, most likely in the elongation mode (Selby and Sancar 1997; Tantin et al. 1997; van Gool et al. 1997a). Possible roles for CSA and CSB in transcription-repair coupling have been discussed recently (van Gool et al. 1997b) and will not be reiterated here. In view of the discussion above, it is interesting to speculate on the role of XPG and TFIIH in this process.

Elongating Pol II complexes track along the template strand in a $3^{\prime} \rightarrow 5^{\prime}$ direction and are expected to position a transcription bubble $3^{\prime}$ of obstructive lesions. In GGNER, recruitment of TFIIH to the damaged site presumably depends on XPC-hHR23B-mediated changes in DNA conformation and protein interactions, whereas XPG recruitment depends on the formation of an opened DNA complex. In transcription-coupled repair the Pol II-induced DNA opening 3' of the lesion may be acces- sible to TFIIH and XPG in the absence of other NER factors. Thus, a stalled Pol II complex may attract TFIIH and XPG independent of the type of lesion causing the block. The in vitro observed interactions between isolated TFIIH subunits and CSA (Henning et al. 1995), XPG and CSB (Iyer et al. 1996), and XPG and TFIIH (Iyer et al. 1996; Mu et al. 1995) may have a role in this recruitment.

The apparently crucial role of the nuclease XPG in transcription-repair coupling is intriguing. The XP-type XP-G patient XP125LO carries a defect in GG-NER and in TC-NER of UV-induced lesions but still displays transcription-coupled repair of oxidative damage (Cooper et al. 1997). The NER defect is caused by an Ala-792 $\rightarrow$ Val substitution next to a presumed catalytic residue, Glu791, in nuclease domain I of XPG (see Fig. 1) (Nouspikel and Clarkson 1994; Shen et al. 1996, 1997). Presumably the mutant protein is inactive in cleavage (Cooper et al. 1997; Nouspikel and Clarkson 1994; Nouspikel et al. 1997; Reardon et al. 1997). On the basis of this assumption, Cooper et al. (1997) suggested that the requirement of XPG for transcription-coupled repair of oxidative damage is independent of its incision activity and may depend on structural properties. Defects in the functions of XPG and TFIIH in transcription-repair coupling are anticipated to interfere with the release of trapped transcription caused by (oxidative) damage (Hanawalt and Mellon 1993; van Gool et al. 1997b).

\section{Excision repair and chromatin}

As is apparent from this review, in vitro NER is fairly well understood. However, most studies have utilized naked DNA as substrate. A major challenge will be to understand the NER process in the context of chromatin, preferably in a living cell. Compaction of DNA into nucleosomes and higher order structures will certainly affect the accessibility of lesions. Repair on the nontranscribed strand of an active gene was found to be rapid in linker DNA and slow in sequences occupied by nucleosomes, whereas TC-NER of the transcribed strand appeared independent of chromatin organization in vivo (Wellinger and Thoma 1997). Two NER components may be important in this context. Purified DDB failed to stimulate repair of naked DNA by XP-E cell extracts, but partially corrected the repair defect upon microinjection in living XP-E cells, suggesting a function of this factor in the repair of UV lesions in chromatin (Rapic Otrin et al. 1998). In yeast, a complex of Rad7-Rad16 (Guzder et al. 1997) functions specifically in GG-NER (Verhage et al. 1994, 1996; Mueller and Smerdon 1995). On the basis of sequence homology, Rad16 belongs to the Swi2/Snf2 subfamily of DNA-dependent ATPases, a group of proteins implicated in chromatin remodelling. Possibly, DDB and as-yet-unidentified human homologs of Rad7Rad16 are involved in lesion-dependent chromatin remodeling in an early stage of global excision repair in vivo.

Repair rates probably depend on both the concentration of repair factors and their affinity for lesions. For 
some NER factors we estimated the presence of $10^{4}-10^{5}$ molecules per nucleus. This indicates that one repair molecule or complex still has to guard $10^{4}-10^{5}$ bp of DNA in human cells. As repair in vivo is highly efficient, repair proteins can be anticipated to act in a highly coordinated fashion in the context of chromatin. Transient association of damaged DNA with the nuclear matrix has been reported (Koehler and Hanawalt 1996). It is not known whether repair in vivo involves the sequential assembly of individual factors or loading of a complete repairosome onto a DNA lesion. By bleaching green fluorescent protein (GFP)-tagged ERCC1-XPF in a subcompartment of the nucleus of a living cell and measuring the rate of influx of fluorescent complexes in the bleached region, it was found that ERCC1-XPF diffuses very rapidly through the nucleus. The diffusion constant is compatible with the majority of ERCC1-XPF being free (i.e., not part of a large NER holocomplex). A significant fraction of ERCC1-XPF complexes became temporarily immobilized on UV exposure as the consequence of actual engagement in repair (A. Houtsmuller, W. Vermeulen, and J.H.J. Hoeijmakers, unpubl.). These findings support a model for NER in vivo involving successive assembly of repair factors in which freely diffusing ERCC1/XPF participates in a distributive fashion. It would be interesting to see whether DNA damage-binding factors like DDB, XPC-hHR23B, and XPA, as well as TFIIH display a similar or a different behavior.

\section{Acknowledgments}

We thank our colleagues in the laboratory for very useful discussions, G.S. Winkler, W. Vermeulen, and A. Houtsmuller for sharing unpublished data, and D. Bootsma for continuous support. Mirko Kuit is acknowledged for help with the illustrations. Our research is supported by the Dutch Scientific Organization (NWO), the Dutch Cancer Society (Koningin Wilhelmina Fonds), the European Community, the Louis Jeantet Foundation, and Human Frontiers.

\section{References}

Aboussekhra, A., M. Biggerstaff, M.K.K. Shivji, J.A. Vilpo, V. Moncollin, V.N. Podust, M. Protic, U. Hübscher, J.-M. Egly, and R.D. Wood. 1995. Mammalian DNA nucleotide excision repair reconstituted with purified components. Cell 80: 859868.

Alani, E., R. Thresher, J.D. Griffith, and R.D. Kolodner. 1992. Characterization of DNA-binding and strand-exchange stimulation properties of y-RPA, a yeast single-strand-DNAbinding protein. J. Mol. Biol. 227: 54-71.

Ariza, R., S. Keyse, J. Moggs, and R.D. Wood. 1996. Reversible protein phosphorylation modulates nucleotide excision repair of damaged DNA by human cell extracts. Nucleic Acids Res. 24: 433-440.

Asahina, H., I. Kuraoka, M. Shirakawa, E.H. Morita, N. Miura, I. Miyamoto, E. Ohtsuka, Y. Okada, and K. Tanaka. 1994. The XPA protein is a zinc metalloprotein with an ability to recognize various kinds of DNA damage. Mutat. Res. 315: 229-237.

Bardwell, A.J., L. Bardwell, N. Iyer, J.Q. Svejstrup, W.J. Feaver, R.D. Kornberg, and E.C. Friedberg. 1994. Yeast nucleotide excision repair proteins Rad2 and Rad4 interact with RNA polymerase II basal transcription factor b (TFIIH). Mol. Cell. Biol. 14: 3569-3576.

Barnes, D.E., A.E. Tomkinson, A.R. Lehmann, A.D.B. Webster, and T. Lindahl. 1992. Mutations in the DNA ligase I gene of an individual with immunodeficiency and cellular hypersensitivity to DNA-damaging agents. Cell 69: 495-503.

Bertrand, P., D.X. Tishkoff, N. Filosi, R. Dasgupta, and R.D. Kolodner. 1998. Physical interaction between components of DNA mismatch repair and nucleotide excision repair. Proc. Natl. Acad. Sci. 95: 14278-14283.

Bessho, T., A. Sancar, L.H. Thompson, and M.P. Thelen. 1997. Reconstitution of human excision nuclease with recombinant XPF-ERCC1complex. J. Biol. Chem. 272: 3833-3837.

Bhui-Kaur, A., M.F. Goodman, and J. Tower. 1998. DNA mismatch repair catalyzed by extracts of mitotic, postmitotic, and senescent Drosophila tissues and involvement of mei-9 gene function for full activity. Mol. Cell. Biol. 18: 14361443.

Biggerstaff, M., D.E. Szymkowski, and R.D. Wood. 1993. Cocorrection of ERCC1, ERCC4, and xeroderma pigmentosum group F DNA repair defects in vitro. EMBO J. 12: 3685-3692.

Blackwell, L.J. and J.A. Borowiec. 1994. Human replication protein A binds single-stranded DNA in two distinct complexes. Mol. Cell. Biol. 14: 3993-4001.

Blackwell, L.J., J.A. Borowiec, and I.A. Masrangelo. 1996. Singlestranded-DNA binding alters human replication protein A structure and facilitates interaction with DNA-dependent protein kinase. Mol. Cell. Biol. 16: 4798-4807.

Bochkarev, A., R. Pfuetzner, A.M. Edwards, and L. Frappier. 1997. Structure of the single-stranded DNA-binding domain of replication protein A bound to DNA. Nature 385: 176181.

Bochkareva, E., L. Frappier, A.M. Edwards, and A. Bochkarev. 1998. The RPA32 subunit of human replication protein A contains a single-stranded DNA-binding domain. J. Biol. Chem. 273: 3932-3936.

Bootsma, D., K.H. Kraemer, J. Cleaver, and J.H.J. Hoeijmakers. 1997. Nucleotide excision repair syndromes: xeroderma pigmentosum, Cockayne syndrome and trichothiodystrophy. In The metabolic basis of inherited disease (ed. C.R. Scriver, A.L. Beaudet, W.S. Sly, and D. Valle). McGraw-Hill Book Co., New York, NY.

Brill, S.J. and S. Bastin-Shanower. 1998. Identification and characterization of the fourth single-stranded-DNA binding domain of replication protein A. Mol. Cell. Biol. 18: 7225-7234.

Brookman, K., J. Lamerdin, M. Thelen, M. Hwang, J. Reardon, A. Sancar, Z. Zhou, C. Walter, C. Parris, and L. Thompson. 1996. ERCC4 (XPF) encodes a human nucleotide excision repair protein with eukaryotic recombination homologs. Mol. Cell. Biol. 16: 6553-6562.

Buchko, G.W. and M.A. Kennedy. 1997. Human nucleotide excision repair protein XPA: $1 \mathrm{H}$ NMR and CD solution studies of a synthetic peptide fragment corresponding to the zincbinding domain (101-141). J. Biomol. Struct. Dyn. 14: 677690.

Buchko, G.W., S. Ni, B.D. Thrall, and M.A. Kennedy. 1998. Structural features of the minimal DNA binding domain (M89-F219) of human nucleotide excision repair protein XPA. Nucleic Acids Res. 26: 2779-2788.

Budd, M.E. and J.L. Campbell. 1995. DNA polymerases required for repair of UV-induced damage in Saccharomyces cerevisiae. Mol. Cell. Biol. 15: 2173-2179.

. 1997. The roles of eukaryotic DNA polymerases in DNA repair synthesis. Mutat. Res. 384: 157-167. 
Burns, J., S. Guzder, P. Sung, S. Prakash, and L. Prakash. 1996. An affinity of human replication protein A for ultravioletdamaged DNA. J. Biol. Chem. 271: 11607-11610.

Busch, D., C. Greiner, K. Lewis, R. Ford, G. Adair, and L. Thompson. 1989. Summary of complementation groups of UV-sensitive $\mathrm{CHO}$ cell mutants isolated by large-scale screening. Mutagenesis 45: 349-354.

Busch, D.B., A.J. van Vuuren, J. de Wit, A. Collins, M.Z. Zdzienicka, D.L. Mitchell, K.W. Brookman, M. Stefanini, R. Riboni, L.H. Thompson, R.B. Albert, A.J. van Gool, and J.H.J. Hoeijmakers. 1997. Phenotypic heterogeneity in nucleotide excision repair mutants of rodent complementation groups 1 and 4. Mutat. Res. 383: 91-106.

Carty, M.P., M. Zernik-Kobak, S. McGrath, and K. Dixon. 1994. UV light-induced DNA synthesis arrest in HeLa cells is associated with changes in phosphorylation of human singlestranded DNA-binding protein. EMBO J. 13: 2114-2123.

Chu, G. and E. Chang. 1988. Xeroderma pigmentosum group E cells lack a nuclear factor that binds to damaged DNA. Science 242: 564-567.

Cloud, K., B. Shen, G. Strniste, and M. Park. 1995. XPG protein has a structure-specific endonuclease activity. Mutat. Res. 347: 55-60.

Clugston, C., K. McLaughlin, M. Kenny, and R. Brown. 1992. Binding of human single-stranded DNA binding protein to DNA damaged by the anticancer drug cis-diamminedichloroplatinum (II). Cancer Res. 52: 6375-6379.

Collins, A.R. 1993. Mutant rodent cell lines sensitive to ultraviolet light, ionizing radiation and cross-linking agents-A comprehensive survey of genetic and biochemical characteristics. Mutat. Res. 293: 99-118.

Conaway, R.C. and J.W. Conaway. 1989. An RNA polymerase II transcription factor has an associated DNA-dependent ATPase (dATPase) activity strongly stimulated by the TATA region of promoters. Proc. Natl. Acad. Sci. 86: 7356-7360.

Cooper, P., T. Nouspikel, S. Clarkson, and S. Leadon. 1997. Defective transcription-coupled repair of oxidative base damage in Cockayne syndrome patients from XP group G. Science 275: 990-993.

Coverley, D., M.K. Kenny, M. Munn, W.D. Rupp, D.P. Lane, and R.D. Wood. 1991. Requirement for the replication protein SSB in human DNA excision repair. Nature 349: 538-541.

Coverley, D., M.K. Kenny, D.P. Lane, and R.D. Wood. 1992. A role for the human single-stranded DNA binding protein HSSB/RPA in an early stage of nucleotide excision repair. Nucleic Acids Res. 20: 3873-3880.

de Boer, J. and J.H.J. Hoeijmakers. 1999. Cancer from the outside, aging from the inside: mouse models to study the consequences of defective nucleotide excision repair. Biochimie (in press).

de Laat, W.L., E. Appeldoorn, N.G.J. Jaspers, and J.H.J. Hoeijmakers. 1998a. DNA structural elements required for ERCC1-XPF endonuclease activity. J. Biol. Chem. 273: 7835-7842.

de Laat, W.L., E. Appeldoorn, K. Sugasawa, E. Weterings, N.G.J. Jaspers, and J.H.J. Hoeijmakers. 1998b. DNA-binding polarity of human replication protein A positions nucleases in nucleotide excision repair. Genes \& Dev. 12: 2598-2609.

de Laat, W.L., A.M. Sijbers, H. Odijk, N.G.J. Jaspers, and J.H.J. Hoeijmakers. 1998c. Mapping of interaction domains between human repair proteins ERCC1 and XPF. Nucleic Acids Res. 26: 4146-4152.

Din, S., S.J. Brill, M.P. Fairman, and B. Stillman. 1990. Cellcycle-regulated phosphorylation of DNA replication factor A from human and yeast cells. Genes \& Dev. 4: 968-977.

Doherty, A.J., L.C. Serpell, and C.P. Ponting. 1996. The helix- hairpin-helix DNA-binding motif: a structural basis for nonsequence-specific recognition of DNA. Nucleic Acids Res. 24: $2488-2497$.

Donahue, B.A., S. Yin, J.-S. Taylor, D. Reines, and P.C. Hanawalt. 1994. Transcript cleavage by RNA polymerase II arrested by a cyclobutane pyrimidine dimer in the DNA template. Proc. Nat1. Acad. Sci. 91: 8502-8506.

Drapkin, R., J.T. Reardon, A. Ansari, J.C. Huang, L. Zawel, K. Ahn, A. Sancar, and D. Reinberg. 1994. Dual role of TFIIH in DNA excision repair and in transcription by RNA polymerase II. Nature 368: 769-772.

Dresler, S. and M. Frattini. 1986. DNA replication and UVinduced DNA repair synthesis in human fibroblasts are much less sensitive than DNA polymerase alpha to inhibition by butylphenyl-deoxyguanosine triphosphate. Nucleic Acids Res. 14: 7093-7102.

Dvir, A., R. Conaway, and J. Conaway. 1996. Promoter escape by RNA polymerase II. A role for an ATP cofactor in suppression of arrest by polymerase at promoter-proximal sites. J. Biol. Chem. 271: 23352-23356.

1997. A role for TFIIH in controlling the activity of early RNA polymerase II elongation complexes. Proc. Natl. Acad. Sci. 94: 9006-9010.

Evans, E., J. Fellows, A. Coffer, and R.D. Wood. 1997a. Open complex formation around a lesion during nucleotide excision repair provides a structure for cleavage by human XPG protein. EMBO J. 16: 625-638.

Evans, E., J. Moggs, J. Hwang, J. Egly, and R.D. Wood. 1997b. Mechanism of open complex and dual incision formation by human nucleotide excision repair factors. EMBO J. 16: 65596573.

Fairman, M.P. and B. Stillman. 1988. Cellular factors required for multiple stages of SV40 DNA replication in vitro. EMBO J. 7: 1211-1218.

Fang, F. and J. Newport. 1993. Distinct roles of cdk2 and cdc2 in RP-A phosphorylation during the cell cycle. J. Cell. Sci. 106: 983-994.

Feaver, W.J., O. Gileadi, and D. Kornberg. 1991. Purification and characterization of yeast RNA polymerase II transcription factor b. J. Biol. Chem. 266: 19000-19005.

Feaver, W.J., J.Q. Svejstrup, L. Bardwell, A.J. Bardwell, S. Buratowski, K.D. Gulyas, T.F. Donahue, E.C. Friedberg, and R.D. Kornberg. 1993. Dual roles of a multiprotein complex from S. cerevisiae in transcription and DNA repair. Cell 75: 13791387.

Feaver, W.J., J.Q. Svejstrup, N.L. Henry, and R.D. Kornberg. 1994. Relationship of CDK-activating kinase and RNA polymerase II CTD kinase TFIIH/TFIIK. Cell 79: 1103-1109.

Fischer, L., M. Gerard, C. Chalut, Y. Lutz, S. Humbert, M. Kanno, P. Chambon, and J.-M. Egly. 1992. Cloning of the 62-kilodalton component of basic transcription factor BTF2. Science 257: 1392-1395.

Fishman-Lobell, J. and J.E. Haber. 1992. Removal of nonhomologous DNA ends in double-strand break recombination: The role of the yeast ultraviolet repair gene RAD1. Science 258: $480-484$.

Flores, O., H. Lu, and D. Reinberg. 1992. Factors involved in specific transcription by mammalian RNA polymerase II. $J$. Biol. Chem. 267: 2786-2790.

Ford, J.M. and P.C. Hanawalt. 1997. Expression of wild-type p53 is required for efficient global genomic nucleotide excision repair in UV-irradiated human fibroblasts. J. Biol. Chem. 272: 28073-28080.

Friedberg, E.C. 1996. Relationships between DNA repair and transcription. Annu. Rev. Biochem. 65: 15-42.

Gary, R., D. Ludwig, H. Cornelius, M. MacInnes, and M. Park. 
1997. The DNA repair endonuclease XPG binds to proliferating cell nuclear antigen (PCNA) and shares sequence elements with the PCNA-binding regions of FEN-1 and cyclindependent kinase inhibitor p21. J. Biol. Chem. 272: 2452224529.

Gerard, M., L. Fischer, V. Moncollin, J.-M. Chipoulet, P. Chambon, and J.-M. Egly. 1991. Purification and interaction properties of the human RNA polymerase B(II) general transcription factor BTF2. J. Biol. Chem. 266: 20940-20945.

Gomes, X. and M. Wold. 1996. Functional domains of the 70kilodalton subunit of human replication protein A. Biochemistry 35: 10558-10568.

Gutz, H. and H. Schmidt. 1985. Switching genes in Schizosaccharomyces pombe. Curr. Genet. 9: 325-331.

Guzder, S.A., V. Bailly, P. Sung, L. Prakash, and S. Prakash. 1995. Yeast DNA repair protein Rad23 promotes complex formation between transcription factor TFIIH and DNA damage recognition factor RAD14. J. Biol. Chem. 270: 83858388.

Guzder, S., P. Sung, L. Prakash, and S. Prakash. 1997. Yeast Rad7-Rad16 complex, specific for the nucleotide excision repair of the nontranscribed DNA strand, is an ATP-dependent DNA damage sensor. J. Biol. Chem. 272: 21665-21668.

Habraken, Y., P. Sung, L. Prakash, and S. Prakash. 1995. Structure-specific nuclease activity in yeast nucleotide excision repair protein Rad2. J. Biol. Chem. 270: 30194-30198.

Habraken, Y., P. Sung, S. Prakash, and L. Prakash. 1996. Transcription factor TFIIH and DNA endonuclease Rad2 constitute yeast nucleotide excision repair factor 3: implications for nucleotide excision repair and Cockayne syndrome. Proc. Nat1. Acad. Sci. 93: 10718-10722.

Hanawalt, P. and I. Mellon. 1993. Stranded in an active gene. Curr. Biol. 3: 67-69.

He, Z., L.A. Henricksen, M.S. Wold, and C.J. Ingles. 1995. RPA involvement in the damage-recognition and incision step of nucleotide excision repair. Nature 374: 566-569.

Henning, K.a., L. Li, N. Iyer, L. McDaniel, M.S. Reagan, R. Legerski, R.A. Schultz, M. Stefanini, A.R. Lehmann, L.V. Mayne, and E.C. Friedberg. 1995. The Cockayne syndrome group A gene encodes a WD repeat protein that interacts with CSB protein and a subunit of RNA polymerase II TFIIH. Cell 82: 555-564.

Hindges, R. and U. Hübscher. 1997. DNA polymerase delta, an essential enzyme for DNA transactions. Biol. Chem. 378: 345-362.

Hirschfeld, S., A.S. Levine, K. Ozato, and M. Protic. 1990. A constitutive damage-specific DNA-binding protein is synthesized at higher levels in UV-irradiated primate cells. Mol. Cell. Biol. 10: 2041-2048.

Hoeijmakers, J.H.J. 1994. Human nucleotide excision repair syndromes: molecular clues to unexpected intricacies. Eur. J. Cancer 30A: 1912-1921.

Holstege, F.C.P., D. Tantin, M. Carey, P.C. van der Vliet, and H.T.M. Timmers. 1995. The requirement for the basal transcription factor IIE is determined by the helical stability of promotor DNA. EMBO J. 14: 810-819.

Holstege, F.C.P., P.C. van der Vliet, and H.T.M. Timmers. 1996. Opening of an RNA polymerase II promoter occurs in two distinct steps and requires the basal transcription factors TFIIE and TFIIH. EMBO J. 15: 1666-1677.

Holstege, F.C.P., U. Fiedler, and H.T.M. Timmers. 1997. Three transitions in the RNA polymerase II transcription complex during initiation. EMBO J. 16: 7468-7480.

Huang, J.C., D.L. Svoboda, J.T. Reardon, and A. Sancar. 1992. Human nucleotide excision nuclease removes thymine dimers from DNA by incising the 22nd phosphodiester bond $5^{\prime}$ and the 6th phosphodiester bond $3^{\prime}$ to the photodimer. Proc. Natl. Acad. Sci. 89: 3664-3668.

Humbert, S., A.J. van Vuuren, Y. Lutz, J.H.J. Hoeijmakers, J.-M. Egly, and V. Moncollin. 1994. Characterization of p44/SSL1 and p34 subunits of the BTF2/TFIIH transcription/repair factor. $E M B O ~ J$. 13: 2393-2398.

Hunting, D., B. Gowans, and S. Dresler. 1991. DNA polymerase delta mediates excision repair in growing cells damaged with ultraviolet radiation. Biochem. Cell. Biol. 69: 303-308.

Hwang, B.J. and G. Chu. 1993. Purification and characterization of a human protein that binds to damaged DNA. Biochemistry 32: 1657-1666.

Hwang, B.J., J.M. Ford, P.C. Hanawalt, and G. Chu. 1999. Expression of the $\mathrm{p} 48$ xeroderma pigmentosum gene is p53 dependent and is involved in global genome repair. Proc. Natl. Acad. Sci. 96: 424-428.

Ikegami, T., I. Kuraoka, M. Saijo, N. Kodo, Y. Kyogoku, K. Morikawa, K. Tanaka, and M. Shirakawa. 1998. Solution structure of the DNA- and RPA-binding domain of the human repair factor XPA. Nat. Struct. Biol. 5: 701-706.

Iyer, N., M.S. Reagan, K.-J. Wu, B. Canagarajah, and E.C. Friedberg. 1996. Interactions involving the human RNA polymerase II transcription/nucleotide excision repair complex $\mathrm{TFIIH}$, the nucleotide excision repair protein XPG, and Cockayne syndrome group B (CSB) protein. Biochemistry 35: 2157-2167.

Jiang, Y., M. Yan, and J. Gralla. 1996. A three-step pathway of transcription initiation leading to promoter clearance at an activation RNA polymerase II promoter. Mol. Cell. Biol. 16: $1614-1621$.

Jones, C.J. and R.D. Wood. 1993. Preferential binding of the xeroderma pigmentosum group A complementing protein to damaged DNA. Biochemistry 32: 12096-12104.

Jonsson, Z. and U. Hübscher. 1997. Proliferating cell nuclear antigen: more than a clamp for DNA polymerases. BioEssays 19: 967-975.

Kataoka, H. and Y. Fujiwara. 1991. UV damage-specific DNAbinding protein in xeroderma pigmentosum complementation group E. Biochem. Biophys. Res. Comm. 175: 1139-1143.

Keeney, S., H. Wein, and S. Linn. 1992. Biochemical heterogeneity in xeroderma pigmentosum complementation group $\mathrm{E}$. Mutat. Res. 273: 49-56.

Keeney, S., G.J. Chang, and S. Linn. 1993. Characterization of human DNA damage binding protein implicated in xeroderma pigmentosum E. J. Biol. Chem. 268: 21293-21300.

Keeney, S., A.P.M. Eker, T. Brody, W. Vermeulen, D. Bootsma, J.H.J. Hoeijmakers, and S. Linn. 1994. Correction of the DNA repair defect in xeroderma pigmentosum group E by injection of a DNA damage-binding protein. Proc. Natl. Acad. Sci. 91: 4053-4056.

Kenny, M.K., S.H. Lee, and J. Hurwitz. 1989. Multiple functions of human single-stranded-DNA binding protein in simian virus 40 DNA replication: single-strand stabilization and stimulation of DNA polymerases alpha and delta. Proc. Nat1. Acad. Sci. 86: 9757-9761.

Kenny, M.K., U. Schlegel, H. Furneaux, and J. Hurwitz. 1990. The role of human single-stranded DNA binding protein and its individual subunits in simian virus 40 DNA replication. J. Biol. Chem. 265: 7693-7700.

Kim, C., R.O. Snyder, and M.S. Wold. 1992. Binding properties of replication protein-A from human and yeast cells. Mol. Cell. Biol. 12: 3050-3059.

Kim, C., B.F. Paulus, and M.S. Wold. 1994. Interactions of human replication protein A with oligonucleotides. Biochemistry 33: 14197-14206. 
Kim, D., E. Stigger, and S. Lee. 1996. Role of the 70-kDa subunit of human replication protein A (I). Single-stranded DNA binding activity, but not polymerase stimulatory activity, is required for DNA replication. J. Biol. Chem. 271: 1512415129.

Klungland, A. and T. Lindahl. 1997. Second pathway for completion of human DNA base excision-repair: reconstitution with purified proteins and requirement for DNase IV (FEN1). EMBO J. 16: 3341-3348.

Koehler, D.R. and P.C. Hanawalt. 1996. Recruitment of damaged DNA to the nuclear matrix in hamster cells following ultraviolet irradation. Nucleic Acids Res. 24: 2877-2884.

Kuraoka, I., E. Morita, M. Saijo, T. Matsuda, K. Morikawa, M. Shirakawa, and K. Tanaka. 1996. Identification of a damaged-DNA binding domain of the XPA protein. Mutat. Res. 362: 87-95.

Leadon, S.A. and A.V. Avrutskaya. 1997. Differential involvement of the human mismatch repair proteins, hMLH1 and hMSH2, in transcription-coupled repair. Cancer Res. 57: 3784-3791.

-1998. Requirement for DNA mismatch repair proteins in the transcription-coupled repair of thymine glycols in Saccharomyces cerevisiae. Mutat. Res. 407: 177-187.

Leadon, S.A. and P.K. Cooper. 1993. Preferential repair of ionizing-radiation induced damage in the transcribed strand of an active human gene is defective in Cockayne syndrome. Proc. Natl. Acad. Sci. 90: 10499-10503.

Leadon, S.A. and D.A. Lawrence. 1992. Strand-specific repair of DNA damage in the yeast $G A L 7$ gene requires RNA polymerase II. J. Biol. Chem. 267: 23175-23182.

Lee, S., Z. Pan, A. Kwong, P. Burgers, and J. Hurwitz. 1991. Synthesis of DNA by DNA polymerase epsilon in vitro. $J$. Biol. Chem. 266: 22707-22717.

Li, L., S.J. Elledge, C.A. Peterson, E.S. Bales, and R.J. Legerski. 1994a. Specific association between the human DNA repair proteins XPA and ERCC1. Proc. Natl. Acad. Sci. 91: 50125016.

Li, R., S. Waga, G.J. Hannon, D. Beach, and B. Stillman. 1994b. Differential effects by the p21 CDK inhibitor on PCNA-dependent DNA replication and repair. Nature 371: 534-537.

Li, L., C.A. Peterson, X. Lu, and R.J. Legerski. 1995a. Mutations in XPA that prevent association with ERCC1 are defective in nucleotide excision repair. Mol. Cell. Biol. 15: 1993-1998.

Li, L., X. Lu, C.A. Peterson, and R.J. Legerski. 1995b. An interaction between the DNA repair factor XPA and replication protein A appears essential for nucleotide excision repair. Mol. Cell. Biol. 15: 5396-5402.

Lieber, M. 1997. The FEN-1 family of structure-specific nucleases in eukaryotic DNA replication, recombination and repair. BioEssays 19: 233-240.

Liu, V.F. and D.T. Weaver. 1993. The ionizing radiation-induced replication protein A phosphorylation response differs between ataxia telangiectasia and normal human cells. Mol. Cell. Biol. 13: 7222-7231.

Longhese, M.P., P. Plevani, and G. Lucchini. 1994. Replication factor A is required in vivo for DNA replication, repair, and recombination. Mol. Cell. Biol. 14: 7884-7890.

Marinoni, J., R. Roy, W. Vermeulen, P. Miniou, Y. Lutz, G. Weeda, T. Seroz, D. Gomez, J. Hoeijmakers, and J. Egly. 1997. Cloning and characterization of p52, the fifth subunit of the core of the transcription/DNA repair factor TFIIH. EMBO I. 16: 1093-1102.

Masutani, C., K. Sugasawa, J. Yanagisawa, T. Sonoyama, M. Ui, T. Enomoto, K. Takio, K. Tanaka, P.J. van der Spek, D. Bootsma, J.H.J. Hoeijmakers, and F. Hanaoka. 1994. Purification and cloning of a nucleotide excision repair complex involving the xeroderma pigmentosum group $\mathrm{C}$ protein and a human homolog of yeast RAD23. EMBO I. 13: 1831-1843.

Masutani, C., M. Araki, K. Sugasawa, P. van der Spek, A. Yamada, A. Uchida, T. Maekawa, D. Bootsma, J. Hoeijmakers, and F. Hanaoka. 1997. Identification and characterization of XPC-binding domain of hHR23B. Mol. Cell. Biol. 17: 69156923.

Matsunaga, T., D. Mu, C.-H. Park, J.T. Reardon, and A. Sancar. 1995. Human DNA repair excision nuclease. Analysis of the roles of the subunits involved in dual incisions by using anti-XPG and anti-ERCC1 antibodies. J. Biol. Chem. 270: 20862-20869.

Matsunaga, T., C.H. Park, T. Bessho, D. Mu, and A. Sancar. 1996. Replication protein A confers structure-specific endonuclease activities to the XPF-ERCC1 and XPG subunits of human DNA repair excision nuclease. J. Biol. Chem. 271: 11047-11050.

Mellon, I. and P.C. Hanawalt. 1989. Induction of the Escherichia coli lactose operon selectively increases repair of its transcribed DNA strand. Nature 342: 95-98.

Mellon, I., G. Spivak, and P.C. Hanawalt. 1987. Selective removal of transcription-blocking DNA damage from the transcribed strand of the mammalian DHFR gene. Cell 51: 241249.

Mellon, I., D.K. Rajpal, M. Koi, C.R. Boland, and G.N. Champe. 1996. Transcription-coupled repair deficiency and mutations in human mismatch repair genes. Science 272: 557-560.

Mitchell, D.L. and R.S. Nairn. 1989. The biology of the (6-4) photoproduct. Photochem. Photobiol. 49: 805-819.

Miyamoto, I., N. Miura, H. Niwa, J. Miyazaki, and K. Tanaka. 1992. Mutational analysis of the structure and function of the xeroderma pigmentosum group A complementing protein. J. Biol. Chem. 267: 12182-12187.

Moggs, J.G., K.J. Yarema, J.M. Essigmann, and R.D. Wood. 1996. Analysis of incision sites produced by human cells extracts and purified proteins during nucleotide excision repair of a 1,3-intrastrand d(GpTpG)-Cisplatin adduct. J. Biol. Chem. 271: 7177-7186.

Moolenaar, G., R. Uiterkamp, D. Zwijnenburg, and N. Goosen. 1998. The C-terminal region of the Escherichia coli UvrC protein, which is homologous to the C-terminal region of the human ERCC1 protein, is involved in DNA binding and 5' incision. Nucleic Acids Res. 26: 462-468.

Morita, E., T. Ohkubo, I. Kuraoka, M. Shirakawa, K. Tanaka, and K. Morikawa. 1996. Implications of the zinc-finger motif found in the DNA-binding domain of the human XPA protein. Genes Cells 1: 437-442.

$\mathrm{Mu}, \mathrm{D}$. and A. Sancar. 1997. Model for XPC-independent transcription-coupled repair of pyrimidine dimers in humans. $J$. Biol. Chem. 272: 7570-7573.

Mu, D., C.-H. Park, T. Matsunaga, D.S. Hsu, J.T. Reardon, and A. Sancar. 1995. Reconstitution of human DNA repair excision nuclease in a highly defined system. J. Biol. Chem. 270: $2415-2418$.

$\mathrm{Mu}$, D., D.S. Hsu, and A. Sancar. 1996. Reaction mechanism of human DNA repair excision nuclease. J. Biol. Chem. 271: 8285-8294.

Mu, D., M. Wakasugi, D. Hsu, and A. Sancar. 1997. Characterization of reaction intermediates of human excision repair nuclease. J. Biol. Chem. 272: 28971-28979.

Mueller, J. and M. Smerdon. 1995. Repair of plasmid and genomic DNA in a rad7s mutant of yeast. Nucleic Acids Res. 23: 3457-3464.

. 1996. Rad23 is required for transcription-coupled repair and efficient overall repair in Saccharomyces cerevisiae. Mol. Cell. Biol. 16: 2361-2368. 
Nichols, A., P. Ong, and S. Linn. 1996. Mutations specific to the xeroderma pigmentosum group E DDB-minus phenotype. J. Biol. Chem. 271: 24317-24320.

Nishida, C., P. Reinhard, and S. Linn. 1988. DNA repair synthesis in human fibroblasts requires DNA polymerase delta. J. Biol. Chem. 263: 501-510.

Nocentini, S., F. Coin, M. Saijo, K. Tanaka, and J.M. Egly. 1997. DNA damage recognition by XPA protein promotes efficient recruitment of transcription factor II H. I. Biol. Chem. 272: 22991-22994.

Nouspikel, T. and S.G. Clarkson. 1994. Mutations that disable the DNA repair gene XPG in a xeroderma pigmentosum group G patient. Hum. Mol. Genet. 3: 963-967.

Nouspikel, T., P. Lalle, S. Leadon, P. Cooper, and S. Clarkson. 1997. A common mutational pattern in Cockayne syndrome patients from xeroderma pigmentosum group G: implications for a second XPG function. Proc. Natl. Acad. Sci. 94: 3116-3121.

O'Donovan, A. and R.D. Wood. 1993. Identical defects in DNA repair in xeroderma pigmentosum group $\mathrm{G}$ and rodent ERCC group 5. Nature 363: 185-188.

O'Donovan, A., A.A. Davies, J.G. Moggs, S.C. West, and R.D. Wood. 1994. XPG endonuclease makes the $3^{\prime}$ incision in human DNA nucleotide excision repair. Nature 371: 432435.

Okhuma, Y. 1997. Multiple functions of general transcription factors TFIIE and TFIIH: possible points of regulation by trans-acting factors. J. Biochem. 122: 481-489.

Pan, Z.-Q., C.-H. Park, A.A. Amin, J. Hurwitz, and A. Sancar. 1995. Phosphorylated and unphosphorylated forms of human single-stranded DNA-binding protein are equally active in simian virus 40 DNA replication and in nucleotide excision repair. Proc. Natl. Acad. Sci. 92: 4636-4640.

Paques, F. and J. Haber. 1997. Two pathways for removal of nonhomologous DNA ends during double-strand break repair in Saccharomyces cerevisiae. Mol. Cell. Biol. 17: 67656771.

Park, C.-H. and A. Sancar. 1994. Formation of a ternary complex by human XPA, ERCC1 and ERCC4 (XPF) excision repair proteins. Proc. Nat1. Acad. Sci. 91: 5017-5021.

Park, C.-H., D. Mu, J.T. Reardon, and A. Sancar. 1995a. The general transcription-repair factor TFIIH is recruited to the excision repair complex by the XPA protein independent of the TFIIE transcription factor. I. Biol. Chem. 270: 4896-4902.

Park, C.-H., T. Bessho, T. Matsunaga, and A. Sancar. 1995b. Purification and characterization of the XPF-ERCC1 complex of human DNA repair excision nuclease. J. Biol. Chem. 270: 22657-22660.

Philipova, D., J. Mullen, H. Maniar, J. Lu, C. Gu, and S. Brill. 1996. A hierarchy of SSB protomers in replication protein A. Genes \& Dev. 10: 2222-2233.

Prigent, C., M. Satoh, G. Daly, D. Barnes, and T. Lindahl. 1994. Aberrant DNA repair and DNA replication due to an inherited enzymatic defect in human DNA ligase I. Mol. Cell. Biol. 14: 310-317.

Rapic Otrin, V., I. Kuraoka, T. Nardo, M. McLenigan, A.P. Eker, M. Stefanini, A.S. Levine, and R.D. Wood. 1998. Relationship of the xeroderma pigmentosum group E DNA repair defect to the chromatin and DNA binding proteins UV-DDB and replication protein A. Mol. Cell. Biol. 18: 3182-3190.

Reardon, J.T., A.F. Nichols, S. Keeney, C.A. Smith, J.S. Taylor, S. Linn, and A. Sancar. 1993. Comparative analysis of binding of human damaged DNA-binding protein (XPE) and Escherichia coli damage recognition protein (UvrA) to the major ultraviolet photoproducts $\mathrm{T}[\mathrm{c}, \mathrm{s}] \mathrm{T}, \mathrm{T}[\mathrm{t}, \mathrm{s}] \mathrm{T}, \mathrm{T}[6-4] \mathrm{T}$, and
T[Dewar]T. J. Biol. Chem. 268: 21301-21308.

Reardon, J.T, D. Mu, and A. Sancar. 1996a. Overproduction, purification, and characterization of the XPC subunit of the human DNA repair excision nuclease. J. Biol. Chem. 271: 19451-19456.

Reardon, J.T., H. Ge, E. Gibbs, A. Sancar, J. Hurwitz, and Z. Pan. 1996b. Isolation and characterization of two human transcription factor IIH (TFIIH)-related complexes: ERCC2/CAK and TFIIH. Proc. Nat1. Acad. Sci. 93: 6482-6487.

Reardon, J.T., T. Bessho, H. Kung, P. Bolton, and A. Sancar. 1997. In vitro repair of oxidative DNA damage by human nucleotide excision repair system: possible explanation for neurodegeneration in xeroderma pigmentosum patients. Proc. Nat1. Acad. Sci. 94: 9463-9468.

Robins, P., C.J. Jones, M. Biggerstaff, T. Lindahl, and R.D. Wood. 1991. Complementation of DNA repair in xeroderma pigmentosum group A cell extracts by a protein with affinity for damaged DNA. EMBO T. 10: 3913-3921.

Rodel, C., S. Kirchhoff, and H. Schmidt. 1992. The protein sequence and some intron positions are conserved between the switching gene swilo of Schizosaccharomyces pombe and the human excision repair gene ERCC1. Nucleic Acids Res. 20: 6347-6353.

Rodel, C., T. Jupitz, and H. Schmidt. 1997. Complementation of the DNA repair-deficient swi10 mutant of fission yeast by the human ERCC1 gene. Nucleic Acids Res. 25: 2823-2827.

Rossignol, M., I. Kolb-Cheynel, and J. Egly. 1997. Substrate specificity of the cdk-activating kinase $(\mathrm{CAK})$ is altered upon association with TFIIH. EMBO J. 16: 1628-1637.

Roy, R., J.P. Adamczewski, T. Seroz, W. Vermeulen, J.-P. Tassan, L. Schaeffer, E.A. Nigg, J.H.J. Hoeijmakers, and J.-M. Egly. 1994a. The MO15 cell cycle kinase is associated with the TFIIH transcription-DNA repair factor. Cell 79: 1093 1101.

Roy, R., L. Schaeffer, S. Humbert, W. Vermeulen, G. Weeda, and J.-M. Egly. 1994b. The DNA-dependent ATPase activity associated with the class II basic transcription factor BTF2/ TFIIH. J. Biol. Chem. 269: 9826-9832.

Rumbaugh, J., R. Murante, S. Shi, and R. Bambara. 1997. Creation and removal of embedded ribonucleotides in chromosomal DNA during mammalian Okazaki fragment processing. J. Biol. Chem. 272: 22591-22599.

Saijo, M., I. Kuraoka, C. Masutani, F. Hanaoka, and K. Tanaka. 1996. Sequential binding of DNA repair proteins RPA and ERCC1 to XPA in vitro. Nucleic Acids Res. 24: 4719-4724.

Sancar, A. 1996. DNA excision repair. Annu. Rev. Biochemistry 65: 43-81.

Schaeffer, L., R. Roy, S. Humbert, V. Moncollin, W. Vermeulen, J.H.J. Hoeijmakers, P. Chambon, and J. Egly. 1993. DNA repair helicase: A component of BTF2 (TFIIH) basic transcription factor. Science 260: 58-63.

Schaeffer, L., V. Moncollin, R. Roy, A. Staub, M. Mezzina, A. Sarasin, G. Weeda, J.H.J. Hoeijmakers, and J.M. Egly. 1994. The ERCC2/DNA repair protein is associated with the class II BTF2/TFIIH transcription factor. EMBO J. 13: 2388-2392.

Scherly, D., T. Nouspikel, J. Corlet, C. Ucla, A. Bairoch, and S.G. Clarkson. 1993. Complementation of the DNA repair defect in xeroderma pigmentosum group $\mathrm{G}$ cells by a human cDNA related to yeast RAD2. Nature 363: 182-185.

Selby, C. and A. Sancar. 1997. Human transcription-repair coupling factor CSB/ERCC6 is a DNA-stimulated ATPase but is not a helicase and does not disrupt the ternary transcription complex of stalled RNA polymerase II. J. Biol. Chem. 272: $1885-1890$.

Serizawa, H., T.M. Mäkelä, J.W. Conaway, R.C. Conaway, R.A. Weinberg, and R.A. Young. 1995. Association of cdk-activat- 
ing kinase subunits with transcription factor TFIIH. Nature 374: 280-282.

Shen, B., J. Nolan, L. Sklar, and M. Park. 1996. Essential amino acids for substrate binding and catalysis of human flap endonuclease 1. J. Biol. Chem. 271: 9173-9176.

- 1997. Functional analysis of point mutations in human flap endonuclease-1 active site. Nucleic Acids Res. 25: 3332 3338.

Shiekhattar, R., F. Mermelstein, R.P. Fisher, R. Drapkin, B. Dynlacht, H.C. Wesselin, D.O. Morgan, and D. Reinberg. 1995. Cdk-activating kinase complex is a component of human transcription factor TFIIH. Nature 374: 283-287.

Shivji, M.K.K., M.K. Kenny, and R.D. Wood. 1992. Proliferating cell nuclear antigen is required for DNA excision repair. Cell 69: $367-374$.

Shivji, M.K.K., A.P.M. Eker, and R.D. Wood. 1994. DNA repair defect in xeroderma pigmentosum group $\mathrm{C}$ and complementing factor from HeLa cells. J. Biol. Chem. 269: 2274922757.

Shivji, M.K.K., V.N. Podust, U. Hübscher, and R.D. Wood. 1995. Nucleotide excision repair DNA synthesis by DNA polymerase $\epsilon$ in the presence of PCNA, RFC, and RPA. Biochemistry 34: 5011-5017.

Sijbers, A.M., W.L. de Laat, R.R. Ariza, M. Biggerstaff, Y.-F. Wei, J.G. Moggs, K.C. Carter, B.K. Shell, E. Evans, M.C. de Jong, S. Rademakers, J. de Rooij, N.G.J. Jaspers, J.H.J. Hoeijmakers, and R.D. Wood. 1996a. Xeroderma pigmentosum group F caused by a defect in a structure-specific DNA repair endonuclease. Cell 86: 811-822.

Sijbers, A.M., P.J. van der Spek, H. Odijk, J. van den Berg, M. van Duin, A. Westerveld, N.G.J. Jaspers, D. Bootsma, and J.H.J. Hoeijmakers. 1996b. Mutational analysis of the human nucleotide excision repair gene ERCC1. Nucleic Acids Res. 24: 3370-3380.

Stigger, E., R. Drissi, and S.H. Lee. 1998. Functional analysis of human replication protein $\mathrm{A}$ in nucleotide excision repair. J. Biol. Chem. 273: 9337-9343.

Sugasawa, K., C. Masutani, A. Uchida, T. Maekawa, P.J. van der Spek, D. Bootsma, J.H.J. Hoeijmakers, and F. Hanaoka. 1996. HHR23B, a human Rad23 homolog, stimulates XPC protein in nucleotide excision repair in vitro. Mol. Cell. Biol. 16: 4852-4861.

Sugasawa, K., J.M.Y. Ng, C. Masutani, T. Maekawa, A. Uchida, P. van der Spek, A. Eker, S. Rademakers, C. Visser, A Aboussekhra, R.D. Wood, F. Hanaoka, D. Bootsma, and J.H.J. Hoeijmakers. 1997. Two human homologs of Rad23 are functionally interchangeable in complex formation and stimulation of XPC repair activity. Mol. Cell. Biol. 17: 69246931.

Sugasawa, K., J.M.Y. Ng, C. Masutani, P.J. van der Spek, A.P.M. Eker, F. Hanaoka, D. Bootsma, and J.H.J. Hoeijmakers. 1998. Xeroderma pigmentosum group $\mathrm{C}$ protein complex is the initiator of global genome nucleotide excision repair. Mol. Cell 2: 223-232.

Sugawara, N., F. Paques, M. Colaiacovo, and J. Haber. 1997. Role of Saccharomyces cerevisiae Msh2 and Msh3 repair proteins in double-strand break-induced recombination. Proc. Natl. Acad. Sci. 94: 9214-9219.

Sung, P., S. Guzder, L. Prakash, and S. Prakash. 1996. Reconstitution of TFIIH and requirement of its DNA helicase subunits, $\operatorname{Rad} 3$ and $\operatorname{Rad} 25$, in the incision step of nucleotide excision repair. J. Biol. Chem. 271: 10821-10826.

Svejstrup, J.Q., Z. Wang, W.J. Feaver, X. Wu, D.A. Bushnell, T.F. Donahue, E.C. Friedberg, and R.D. Kornberg. 1995. Different forms of TFIIH for transcription and DNA repair: holo-TFIIH and a nucleotide excision repairosome. Cell 80: 21-28.
Tanaka, K., N. Miura, I. Satokata, I. Miyamoto, M.C. Yoshida, Y. Satoh, S. Kondo, A. Yasui, H. Okayama, and Y. Okada. 1990. Analysis of a human DNA excision repair gene involved in group A xeroderma pigmentosum and containing a zinc-finger domain. Nature 348: 73-76.

Tantin, D., A. Kansal, and M. Carey. 1997. Recruitment of the putative transcription-repair coupling factor CSB/ERCC6 to RNA polymerase II elongation complexes. Mol. Cell. Biol. 17: 6803-6814.

Tijsterman, M., R. Verhage, P. van de Putte, J. Tasseron-de Jong, and J. Brouwer. 1997. Transitions in the coupling of transcription and nucleotide excision repair within RNA polymerase II-transcribed genes of Saccharomyces cerevisiae. Proc. Nat1. Acad. Sci. 94: 8027-8032.

Tomkinson, A. and D. Levin. 1997. Mammalian DNA ligases. BioEssays 19: 893-901.

Tsurimoto, T., M. Fairman, and B. Stillman. 1989. Simian virus 40 DNA replication in vitro: identification of multiple stages of initiation. Mol. Cell. Biol. 9: 3839-3849.

Tu, Y., S. Bates, and G. Pfeifer. 1997. Sequence-specific and domain-specific DNA repair in xeroderma pigmentosum and Cockayne syndrome cells. J. Biol. Chem. 272: 20747-20755.

van der Spek, P.J., A. Eker, S. Rademakers, C. Visser, K. Sugasawa, C. Masutani, F. Hanaoka, D. Bootsma, and J.H. Hoeijmakers. 1996. XPC and human homologs of RAD23: intracellular localization and relationship to other nucleotide excision repair complexes. Nucleic Acids Res. 24: 2551-2559.

van Duin, M., J. de Wit, H. Odijk, A. Westerveld, A. Yasui, M.H.M. Koken, J.H.J. Hoeijmakers, and D. Bootsma. 1986. Molecular characterization of the human excision repair gene ERCC-1: cDNA cloning and amino acid homology with the yeast DNA repair gene RAD10. Cell 44: 913-923.

van Gool, A.J., E. Citterio, S. Rademakers, R. van Os, W. Vermeulen, A. Constantinou, J. Egly, D. Bootsma, and J.H.J. Hoeijmakers. 1997a. The Cockayne syndrome B protein, involved in transcription-coupled DNA repair, resides in an RNA polymerase II-containing complex. EMBO J. 16: 59555965.

van Gool, A.J., G.T.J. van der Horst, E. Citterio, and J.H.J. Hoeijmakers. 1997b. Cockayne syndrome: defective repair of transcription? EMBO J. 16: 4155-4162.

van Hoffen, A., A.T. Natarajan, L.V. Mayne, A.A. van Zeeland, L.H.F. Mullenders, and J. Venema. 1993. Deficient repair of the transcribed strand of active genes in Cockayne syndrome. Nucleic Acids Res. 21: 5890-5895.

van Hoffen, A., J. Venema, R. Meschini, A.A. van Zeeland, and L.H.F. Mullenders. 1995. Transcription-coupled repair removes both cyclobutane pyrimidine dimers and 6-4 photoproducts with equal efficiency and in a sequential way from transcribed DNA in xeroderma pigmentosum group C fibroblasts. EMBO J. 14: 360-367.

van Vuuren, A.J., E. Appeldoorn, H. Odijk, A. Yasui, N.G.J. Jaspers, D. Bootsma, and J.H.J. Hoeijmakers. 1993. Evidence for a repair enzyme complex involving ERCC1 and complementing activities of ERCC4, ERCC11 and xeroderma pigmentosum group F. EMBO J. 12: 3693-3701.

van Vuuren, A.J., W. Vermeulen, L. Ma, G. Weeda, E. Appeldoorn, N.G.J. Jaspers, A.J. van der Eb, D. Bootsma, J.H.J. Hoeijmakers, S. Humbert, L. Schaeffer, and J.-M. Egly. 1994. Correction of xeroderma pigmentosum repair defect by basal transcription factor BTF2 (TFIIH). EMBO T. 13: 1645-1653.

Venema, J., A. Van Hoffen, A.T. Natarajan, A.A. Van Zeeland, and L.H.F. Mullenders. 1990a. The residual repair capacity of xeroderma pigmentosum complementation group $\mathrm{C}$ fibroblasts is highly specific for transcriptionally active DNA. Nucleic Acids Res. 18: 443-448. 
Venema, J., L.H.F. Mullenders, A.T. Natarajan, A.A. Van Zeeland, and L.V. Mayne. 1990b. The genetic defect in Cockayne syndrome is associated with a defect in repair of UVinduced DNA damage in transcriptionally active DNA. Proc. Natl. Acad. Sci. 87: 4707-4711.

Venema, J., A. van Hoffen, V. Karcagi, A.T. Natarajan, A.A. van Zeeland, and L.H.F. Mullenders. 1991. Xeroderma pigmentosum complementation group $\mathrm{C}$ cells remove pyrimidine dimers selectively from the transcribed strand of active genes. Mol. Cell. Biol. 11: 4128-4134.

Verhage, R.A., A. Zeeman, N. de Groot, F. Gleig, D. Bang, P. van der Putte, and J. Brouwer. 1994. The RAD7 and RAD16 genes are essential for repair of non-transcribed DNA in Saccharomyces cerevisiae. Mol. Cell. Biol. 14: 6135-6142.

Verhage, R.A., A.J. Van Gool, N. De Groot, J.H.J. Hoeijmakers, P. Van de Putte, and J. Brouwer. 1996. Double mutants of Saccharomyces cerevisiae with alterations in global genome and transcription-coupled repair. Mol. Cell. Biol. 16: 496502.

Vermeulen, W., A.J. van Vuuren, M. Chipoulet, L. Schaeffer, E. Appeldoorn, G. Weeda, N.G.J. Jaspers, A. Priestley, C.F. Arlett, A.R. Lehmann, M. Stefanini, M. Mezzina, A. Sarasin, D. Bootsma, J.-M. Egly, and J.H.J. Hoeijmakers. 1994. Three unusual repair deficiencies associated with transcription factor BTF2(TFIIH). Evidence for the existence of a transcription syndrome. Cold Spring Harb. Symp. Quant. Biol. 59: 317329.

Waga, S., G.J. Hannon, D. Beach, and B. Stillman. 1994a. The p21 inhibitor of cyclin-dependent kinases controls DNA replication by interaction with PCNA. Nature 369: 574-578.

Waga, S., G. Bauer, and B. Stillman. 1994b. Reconstitution of complete SV40 DNA replication with purified replication factors. J. Biol. Chem. 269: 10923-10934.

Wakasugi, M. and A. Sancar. 1998. Assembly, subunit composition, and footprint of human DNA repair excision complex. Proc. Nat1. Acad. Sci. 95: 6669-6674.

Wakasugi, M., J. Reardon, and A. Sancar. 1997. The non-catalytic function of XPG protein during dual incision in human nucleotide excision repair. J. Biol. Chem. 272: 16030-16034.

Wang, Z., J.Q. Svejstrup, W.J. Feaver, X. Wu, R.D. Kornberg, and E.C. Friedberg. 1994. Transcription factor b (TFIIH) is required during nucleotide excision repair in yeast. Nature 368: 74-76.

Wang, Z., S. Buratowski, J.Q. Svejstrup, W.J. Feaver, X. Wu, R.D. Kornberg, T.D. Donahue, and E.C. Friedberg. 1995. The yeast TFB1 and SSL1 genes, which encode subunits of transcription factor $\mathrm{IIH}$, are required for nucleotide excision repair and RNA polymerase II transcription. Mol. Cell. Biol. 15: 2288-2293.

Watkins, J.F., P. Sung, L. Prakash, and S. Prakash. 1993. The Saccharomyces cerevisiae DNA repair gene RAD23 encodes a nuclear protein containing a ubiquitin-like domain required for biological function. Mol. Cell. Biol. 13: 7757-7765.

Wellinger, R. and F. Thoma. 1997. Nucleosome structure and positioning modulate nucleotide excision repair in the nontranscribed strand of an active gene. EMBO J. 16: 5046-5056.

Winkler, G., W. Vermeulen, F. Coin, J. Egly, J. Hoeijmakers, and G. Weeda. 1998. Affinity purification of human DNA repair/ transcription factor TFIIH using epitope-tagged xeroderma pigmentosum B protein. J. Biol. Chem. 273: 1092-1098.

Wobbe, C., L. Weissbach, J. Borowiec, F. Dean, Y. Murakami, P. Bullock, and J. Hurwitz. 1987. Replication of simian virus 40 origin-containing DNA in vitro with purified proteins. Proc. Natl. Acad. Sci. 84: 1834-1838.

Wold, M.S. 1997. Replication protein A: a heterotrimeric, single-stranded DNA-binding protein required for eukary- otic DNA metabolism. Annu. Rev. Biochem. 66: 61-92.

Wold, M.S. and T. Kelly. 1988. Purification and characterization of replication protein $\mathrm{A}$, a cellular protein required for in vitro replication of simian virus 40 DNA. Proc. Natl Acad. Sci. 85: 2523-2527.

Wold, M.S., D. Weinberg, D. Virshup, J. Li, and T. Kelly. 1989. Identification of cellular proteins required for simian virus 40 DNA replication. J. Biol. Chem. 264: 2801-2809.

Wood, R.D. 1996. DNA repair in eukaryotes. Annu. Rev. Biochem. 65: 135-167.

- 1997. Nucleotide excision repair in mammalian cells. $J$. Biol. Chem. 272: 23465-23468.

Wood, R.D. and M.K.K. Shivji. 1997. Which DNA polymerases are used for DNA-repair in eukaryotes? Carcinogenesis 18: $605-610$

Wu, X., J. Li, X. Li, C. Hsieh, P. Burgers, and M. Lieber. 1996. Processing of branched DNA intermediates by a complex of human FEN-1 and PCNA. Nucleic Acids Res. 24: 2036-2043.

Yagi, T., R.D. Wood, and H. Takebe. 1997. A low content of ERCC1 and a $120 \mathrm{kDa}$ protein is a frequent feature of group F xeroderma pigmentosum fibroblast cells. Mutagenesis 12: $41-44$

Yan, M. and J. Gralla. 1997. Multiple ATP-dependent steps in RNA polymerase II promoter melting and initiation. EMBO J. 16: 7457-7467. 


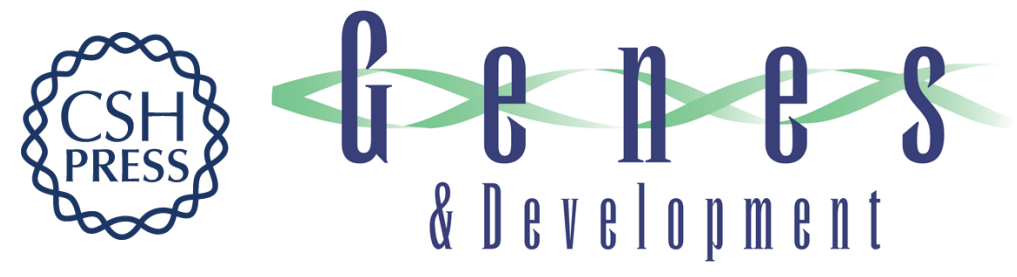

\section{Molecular mechanism of nucleotide excision repair}

Wouter L. de Laat, Nicolaas G.J. Jaspers and Jan H.J. Hoeijmakers

Genes Dev. 1999, 13:

References This article cites 210 articles, 119 of which can be accessed free at: http://genesdev.cshlp.org/content/13/7/768.full.html\#ref-list-1

License

Email Alerting

Receive free email alerts when new articles cite this article - sign up in the box at the top Service right corner of the article or click here.

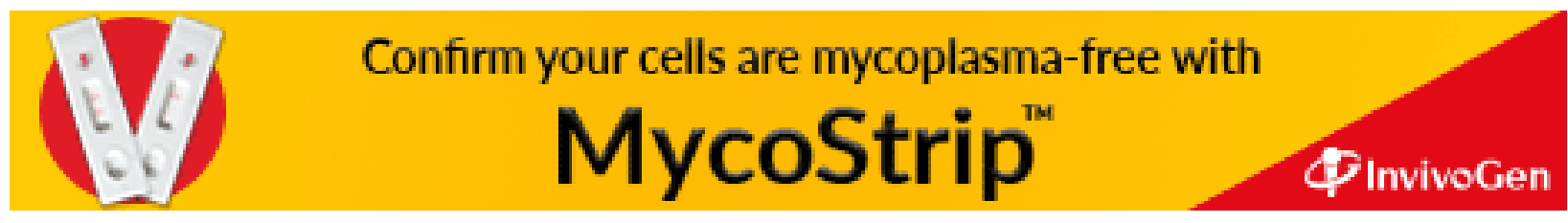

